\title{
Palladium-catalyzed enantioselective carbonylation reactions
}

\author{
Jin-Bao Peng ${ }^{1 *}$, Xin-Lian $\mathrm{Liu}^{1 \dagger}, \mathrm{Lin}^{\mathrm{Li}^{1 \dagger}}$ \& Xiao-Feng $\mathrm{Wu}^{2,3^{*}}$ \\ ${ }^{1}$ School of Biotechnology and Health Sciences, Wuyi University, Jiangmen 529020, China; \\ ${ }^{2}$ Dalian National Laboratory for Clean Energy, Dalian Institute of Chemical Physics, Chinese Academy of Sciences, Liaoning 116023, China; \\ ${ }^{3}$ Leibniz-Institut für Katalyse e.V., Albert-Einstein-Straße 29a, Rostock 18059, Germany
}

Received October 14, 2021; accepted November 15, 2021; published online January 5, 2022

\begin{abstract}
Carbonylation, one of the most powerful approaches to the preparation of carbonylated compounds, has received significant attention from researchers active in various fields. Indeed, impressive progress has been made on this subject over the past few decades. Among the various types of carbonylation reactions, asymmetric carbonylation is a straightforward methodology for constructing chiral compounds. Although rhodium-catalyzed enantioselective hydroformylations have been discussed in several elegant reviews, a general review on palladium-catalyzed asymmetric carbonylations is still missing. In this review, we summarize and discuss recent achievements in palladium-catalyzed asymmetric carbonylation reactions. Notably, this review's contents are categorized by reaction type.
\end{abstract}

palladium catalyst, enantioselective, carbonylation, chiral

Citation: Peng JB, Liu XL, Li L, Wu XF. Palladium-catalyzed enantioselective carbonylation reactions. Sci China Chem, 2022, 65: 441-461, https://doi.org/ 10.1007/s11426-021-1165-6

\section{Introduction}

\subsection{Background of enantioselective carbonylation reactions}

Carbonylation reactions are fundamental and promising approaches to the preparation of a range of carbonyl-containing compounds [1]. Since its discovery, the transition metalcatalyzed carbonylation reaction has been widely studied, and it has become an extremely useful synthetic tool in organic chemistry. It has now become one of the most important homogeneous industrial processes; indeed, many carbonylative procedures have been adapted for the production of fine chemicals at an industrial scale. For example, the annual production of oxo chemicals runs into millions of tons; the vast majority of the world's acetic acid production is based on the carbonylation of methanol (Monsanto or Cativa $^{\mathrm{TM}}$ process). In addition, given its efficiency and atom

\footnotetext{
*Corresponding authors (email: pengjb_05@126.com; Xiao-Feng.Wu@catalysis.de)
} $\dagger$ These authors contributed equally to this work. economy, the carbonylation reaction has emerged as one of the ideal methods for the synthesis of carbonyl compounds, and it has been implemented as a key step in the synthesis of natural products and pharmaceuticals [2]. For example, the process for the production of ibuprofen developed by BHC Company, which only involves three steps and affords high value of atomic economy of $77 \%$, represents an ideal example of a green chemistry synthetic approach; in fact, this process has won the Presidential Green Chemistry Challenge Award in 1997 (Scheme 1).

In the case of ibuprofen, the final product is racemic, and it has been used as an anti-inflammatory and analgesic agent for over 30 years. Although the two enantiomers of ibuprofen exhibit similar pharmacological properties, the $(S)$-enantiomer is 28 times more active than the $(R)$-enantiomer. Notably, only a single enantiomer is used pharmaceutically in the case of other related aryl propanoic acid drugs, such as naproxen and flurbiprofen. In fact, the demand for optically pure compounds is continuously growing; for example, 114 out of the 200 commonly used drugs in the clinical context 


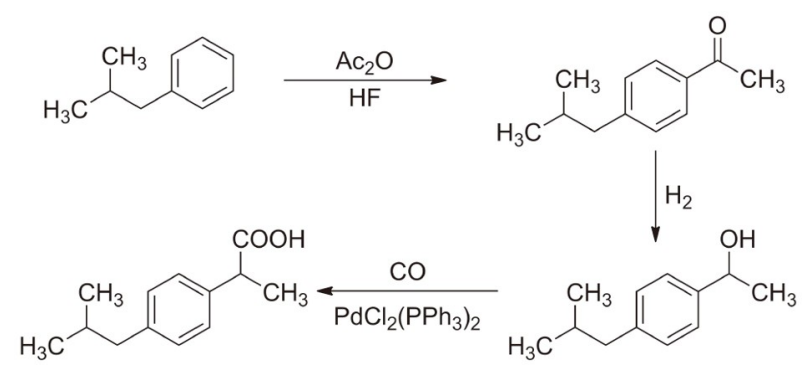

Scheme 1 BHC process for ibuprofen synthesis.

are chiral compounds. Thus, the development of stereoselective asymmetric transformations of organic compounds is a very interesting subject as well as a challenging goal of modern synthetic chemistry.

In addition to the direct extraction from natural chiral compounds, four main approaches are currently employed to access enantiomerically pure chiral organic molecules: (1) resolution of racemic compounds; (2) asymmetric induction from natural chiral compounds; (3) enzymatic and biocatalytic asymmetric transformations; and (4) asymmetric catalysis. Among them, asymmetric catalysis is the most versatile and powerful, and, as such, it has attracted a great deal of attention. Over the past few decades, important successes have been achieved in this field.

As for carbonylation, although the carbonyl group is a planar structure without chirality, one of the most important research objectives in this area is the development of carbonylation reactions that can be implemented for the enantioselective synthesis of carbonyl compounds bearing an $\alpha$-stereocenter, a $\beta$-stereocenter, or axial chirality. However, several challenges exist that render the enantioselective carbonylation difficult and complicated. For example, the competitive coordination between $\mathrm{CO}$ and the chiral ligands with the transition metal catalysts would directly restrain the chiral introduction; the strong $\pi$-acidity and coordination ability of $\mathrm{CO}$ also reduces the activities of low-valence metal species; harsh reaction conditions (i.e., high temperature and high CO pressure) would lead to the incidental racemization of carbonyl compounds bearing an $\alpha$-H stereocenter. In addition, the $\beta$-hydrogen elimination of alkyl-palladium intermediates and other competitive side reactions render the enantioselective carbonylation reaction a daunting challenge.

\subsection{Scope of this review}

Performing highly enantioselective carbonylation reactions remains a challenging undertaking; however, over the past decades, substantial improvements have been made in this field. In particular, the development of chiral ligands has provided broad opportunities to successfully implement these transformations. Although several transition metals have been employed as catalysts in a wide range of asym- metric carbonylative transformations [3], the main achievements in enantioselective carbonylation are the Rh-catalyzed hydroformylation and Pd-catalyzed hydroxycarbonylation and alkoxycarbonylation of olefins. Recently, Pd-catalyzed carbonylation reactions have also been performed in the synthesis of chiral cyclic compounds and axially chiral compounds. Even though rhodium-catalyzed enantioselective hydroformylation reactions have been discussed in several elegant reviews [4], a general review focusing on palladium-catalyzed asymmetric carbonylation reactions is still missing. This review aims to summarize the recent achievements and important advances in palladiumcatalyzed enantioselective carbonylation reactions organized based on reaction type.

\section{Palladium-catalyzed hydrocarbonylations}

\subsection{Palladium-catalyzed intermolecular hydroalk- oxycarbonylations}

Pd-catalyzed alkoxycarbonylations and hydroxycarbonylations of alkenes are of great importance in organic chemistry, as they have a variety of useful applications in homogeneous catalysis [5]. The multi-ton-scale production of methyl propionate via the methoxycarbonylation of ethene represents one of the key applications of this powerful transformation. In addition, the asymmetric branched-selective carbonylation of styrene derivatives provides an ideal strategy for the preparation of aryl propanoic acid drugs (e.g., ibuprofen and naproxen). However, the implementation of this reaction has proven very challenging due to difficulties associated with the simultaneous control of enantioselectivity and regioselectivity. In general, monophosphine ligands favor branched regioselectivity, but they afford poor enantioselectivity; by contrast, the use of diphosphines mainly results in linear products [6]. The Clarke group [7] developed a class of Pd catalysts derived from the planar chiral Phanephos ligands. Both dipalladium and monopalladium complexes of the Phanephos ligands could be prepared to employ the appropriate stoichiometry. These dimetallic complexes were discovered to catalyze both the hydroxycarbonylation and methoxycarbonylation of several alkenes, including vinyl arenes, with high enantioselectivity (Scheme 2). The hydroxycarbonylation of norbornene with $(R)$-2-1di delivered the corresponding chiral acid in $63 \%$ yield with high exo/ endo selectivity and up to $92 \%$ enantiomeric excess (ee). The $\left[\mathrm{Pd}_{2} \mathrm{Cl}_{4}\left(\mathrm{~F}_{24}\right.\right.$-Phanephos) $]$ dimer (2-3di) was found to be especially suitable for the catalysis of the methoxycarbonylation of styrene. Indeed, with this complex, the simultaneous control of regioselectivity (branched-to-linear ratio $>99.9: 0.1)$ and enantioselectivity $(80 \%$ ee) has been realized. An intermolecular methoxycarbonylation of vinyl arene accomplished using the $\mathrm{PdCl}_{2}((S)$-xylyl-Phanephos) 


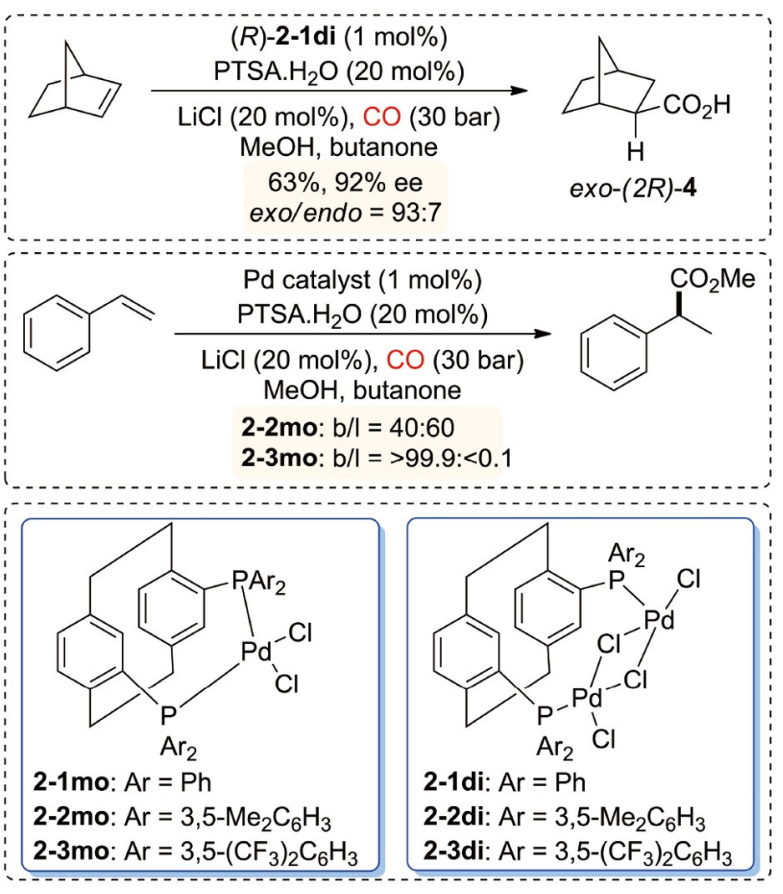

Scheme 2 Pd-catalyzed alkoxycarbonylation and hydroxycarbonylation of alkenes (color online).

catalyst ((S)-2-2mo) was used in a two-step synthesis of $(S)$ flurbiprofen methyl ester from commercially available 4bromo-2-fluoro-1,1'-biphenyl [8]. The reaction mechanism of this $\mathrm{Pd} / \mathrm{Phanephos-catalyzed} \mathrm{methoxycarbonylation} \mathrm{of}$ styrene was investigated based on density functional theory (DFT) computations supported by the results of deuterium labeling studies [9]. Coordination of alkene to a Pd-hydride species was identified as the origin of asymmetric induction and regioselectivity and rationalized according to a quadrantdiagram representation.

The $\mathrm{Pd}(\mathrm{OAc})_{2} /(R)-(-)$-DTBM-SEGPHOS catalytic system was utilized by the Shi group [10] for the enantioselective hydroesterification of aryl olefins with phenyl formate (Scheme 3). As a result of the described reaction, a range of phenyl 2-arylpropanoates were obtained in high yield and $87 \%-95 \%$ ee.

The main challenge of the enantioselective hydrocarbonylation reaction resides in the difficulty of controlling the multi-selectivities (chemoselectivity, siteselectivity, and stereoselectivity) and the occurrence of side-reactions, such as the isomerization of the double bond. Therefore, the asymmetric hydrocarbonylation of olefins is typically limited to vinylarenes and their analogs. Very recently, Dong and co-workers [11] reported the highly efficient asymmetric alkoxycarbonylation and hydroxycarbonylation of $\beta$-carbonyl-functionalized alkenes (Scheme 4). In these reactions, the multi-selectivity issues associated with implementing asymmetric hydrocarbonylations were alleviated by introducing a carbonyl group as the directing group (DG) in the

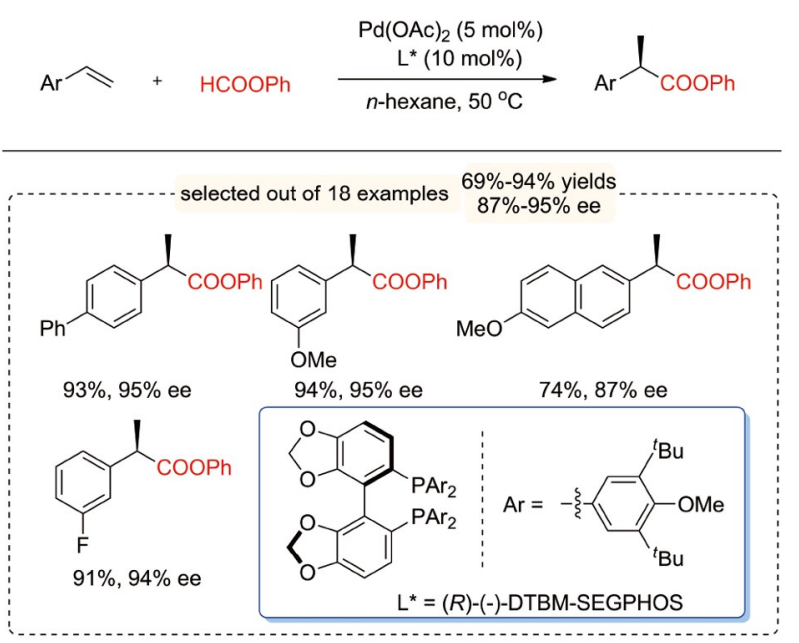

Scheme 3 Pd-catalyzed hydroesterification of aryl olefins with phenyl formate (color online).

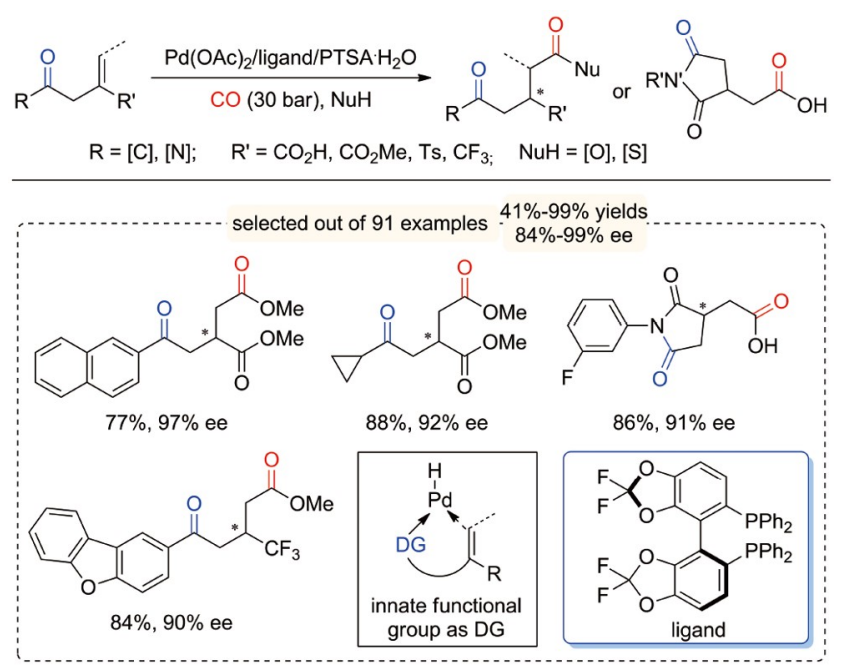

Scheme 4 Pd-catalyzed alkoxycarbonylation and hydroxycarbonylation of $\beta$-carbonyl-functionalized alkenes (color online).

$\beta$-position of the olefinic substrate, which was demonstrated to be not only crucial for controlling the reaction's chemoselectivity and stereoselectivity but also for increasing catalytic activity. Notably, the $\mathrm{Pd}(\mathrm{OAc})_{2} /(\mathrm{S})$-Difluorphos/ PTSA $\cdot \mathrm{H}_{2} \mathrm{O}$ catalyst system was used, and, as a result, various densely functionalized chiral molecules with high optical purity ( $>90$ examples, $84 \%-99 \%$ ee) were prepared from broadly available alkenes, $\mathrm{CO}$, and nucleophiles. The results of control experiments and DFT calculations revealed that the $\beta$-carbonyl group, which facilitates chiral induction via the coordination of the transition metal, played a key role in determining the reaction's enantioselectivity and promoting catalytic activity. Moreover, the presence of an electron-withdrawing vinyl substituent (e.g., $-\mathrm{CO}_{2} \mathrm{H},-\mathrm{CO}_{2}$ $\mathrm{Me},-\mathrm{Ts}$, or $-\mathrm{CF}_{3}$ ) was vital to inhibiting the carbocationinduced alkene isomerization. 


\subsection{Palladium-catalyzed intramolecular hydroalk- oxycarbonylations}

Alper et al. [12] extensively studied the Pd-catalyzed cyclocarbonylation of allylic alcohols for the synthesis of $\gamma-$ butyrolactones (Scheme 5). In order to achieve high enantioselectivity and catalytic activity in Pd-catalyzed asymmetric cyclocarbonylation reactions, it is essential to find a suitable ligand that may meet the following two primary requirements: (1) conformational rigidity of the Pd-bisphosphine complexes, which favors the efficient introduction of chirality in the product; (2) a flexible metal-ligand chelate framework, which is necessary for efficient $\mathrm{CO}$ insertion [13]. In 1997, Alper and co-workers [14] developed the first enantioselective variant of this reaction using a chiral palladium complex generated in situ by mixing $\left[\mathrm{Pd}_{2}(\mathrm{dba})_{3}\right]$. $\mathrm{CHCl}_{3}$ with a commercially available chiral bisphosphine ligand (-)-BPPM. The asymmetric cyclocarbonylation of allylic alcohols with aliphatic substituents was found to proceed with lower enantioselectivity than the analogous reaction conducted with substrates containing aromatic substituents. Up to $84 \%$ ee could be achieved in the cyclocarbonylation of aryl-substituted allylic alcohols in the presence of the $\mathrm{Pd} /(-)$-BPPM catalyst to produce the corresponding $\gamma$-butyrolactones. Recrystallization of some lactones could improve product enantiopurity to $>98 \%$ ee. However, only $\beta$-substituted allylic alcohols with geminal dialkyl substitution at the $\alpha$-position were reported in this asymmetric cyclocarbonylation reaction. A palladium hydride species was believed to play a key role in this reaction (Scheme 5, bottom). The preferential formation of an intermediate where the carbon skeleton fits into the chiral scaffold of (-)-BPPM is believed to bring about enantioselectivity.

Alper's and van Leeuwen's studies demonstrated that the rate of $\mathrm{CO}$ insertion into a Pd-alkyl bond decreases in the following order: 1,4-bisphosphine $>$ 1,3-bisphosphine $>>$ 1,2-bisphosphine. The use of a relatively flexible sevenmembered ring 1,4-bisphosphine ligand for ligand-metal chelation favors the Pd-catalyzed carbonylation reaction. Zhang et al. [15] developed a $C_{2}$ symmetric chiral 1,4-bisphosphine, $\left(2 R, 2^{\prime} R\right)$-bis(diphenylphosphanyl)-(1R,1'R)-dicyclopentane (BICP), whose backbone comprises two cyclopentane rings, and, through its use, they were able to achieve high enantioselectivity in a number of Rh-catalyzed and Ru-catalyzed asymmetric hydrogenation reactions. In 1999, the same research group reported a highly enantioselective asymmetric cyclocarbonylation of allylic alcohols catalyzed by $\mathrm{Pd}$ complexes with BICP and related ligands (Scheme 6) [16]. Both geminally disubstituted allylic alcohols and $\beta, \gamma$-substituted allylic alcohols without dialkyl substituents at the $\alpha$ position were tolerated, and their use as substrates produced the corresponding $\gamma$-butyrolactones.
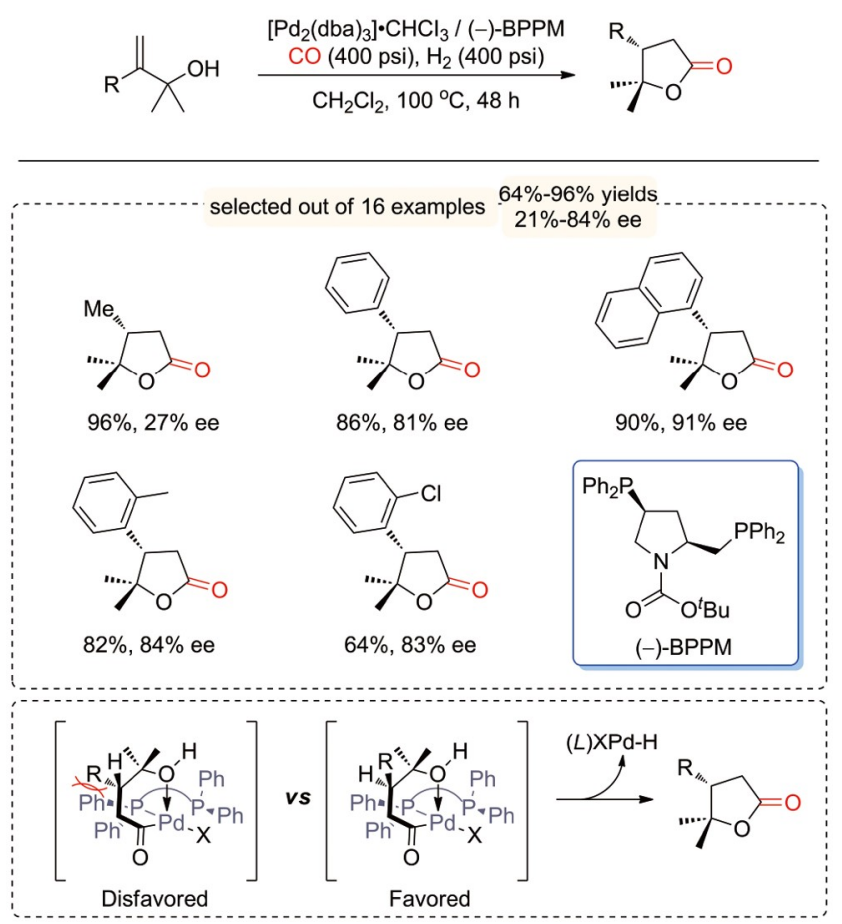

Scheme 5 Pd-BPPM-catalyzed cyclocarbonylation of allylic alcohols (color online).
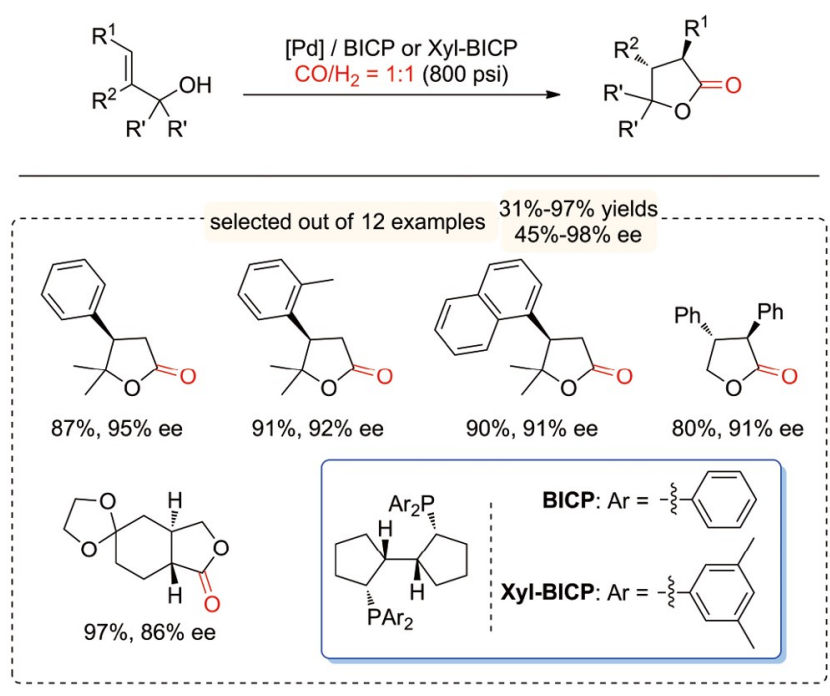

Scheme 6 Pd-BICP-catalyzed cyclocarbonylation of allylic alcohols (color online).

High enantioselectivities of up to $98 \%$ ee were obtained. The cyclocarbonylation of $\beta, \gamma$-disubstituted allylic alcohols generated trans chiral $\gamma$-butyrolactones, indicating a cis $\mathrm{Pd}-$ $\mathrm{H}$ migratory insertion into the allylic $\mathrm{C}=\mathrm{C}$ bond.

The hydroesterification of olefins (Reppe carbonylation) is a powerful transformation that affords the conversion of olefins, carbon monoxide, and alcohols into valuable carbonyl compounds under conditions of transition metal catalysis. Indeed, the Reppe carbonylation has been widely used for the industrial production of drugs, materials, and fine 
chemicals. However, the development of asymmetric hydroesterification reactions remains a slow undertaking due to the lack of highly efficient and stereoselective catalytic systems, especially when tertiary alcohols are used as substrates. In 2014, Shi and co-workers [17] developed an efficient Pd-catalyzed hydroesterification of alkenylphenol using phenyl formate as $\mathrm{CO}$ source for the synthesis of benzofuran-2(3H)-ones and 3,4-dihydrocoumarins (Scheme 7). In one case, a $76 \%$ ee was obtained when a chiral ligand, (R)-(-)-DTBM-SEGPHOS, was used [18]. Soon after, the same group conducted a more in-depth investigation into this enantioselective hydroesterification process [19].

Recently, Claverie, Tang, and co-workers [20] developed an efficient asymmetric hydroesterification of diarylmethyl carbinols that relied on a Pd-WingPhos catalyst. The same group realized the Pd-catalyzed asymmetric hydroesterification of both 1,1-diaryl olefins and diarylmethyl carbinols using the $(R, R, R, R)$-WingPhos ligand that they had developed [21]; by this approach, the study authors obtained a series of chiral 4-aryl-3,4-dihydrocoumarins via reactions characterized by excellent enantioselectivities and good yields. A plausible stereochemical model was proposed that included the Pd-WingPhos catalyst (Scheme 8, bottom). In addition, the described approach was successfully used in a four-step asymmetric synthesis of the muscarinic antagonist $(R)$-tolterodine from readily available starting materials.

\subsection{Palladium-catalyzed hydrothiocarbonylations}

The asymmetric thiocarbonylation of alkenes whereby thiols are employed instead of alcohols as nucleophiles provide a straightforward approach to the synthesis of thioesters. However, this methodology suffers from some shortcomings, such as the loss of catalyst activity due to the strong binding affinities between thiols and late transition metals, as

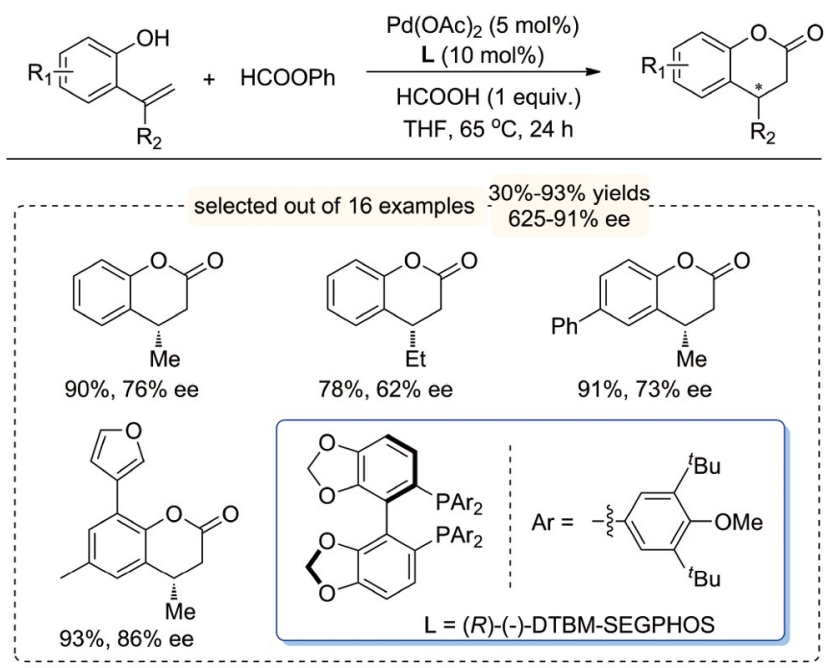

Scheme 7 Pd-catalyzed hydroesterification of alkenylphenol (color online). well as the weakness of the $\mathrm{S}-\mathrm{H}$ bonds, which may favor homolytic bond cleavage to produce the thiyl radical [22]. In 2001, Xiao and Alper [23] developed an asymmetric thiocarbonylation of 1,3-dienes to produce $\beta, \gamma$-unsaturated thiol esters based on a $\mathrm{Pd}(\mathrm{OAc})_{2} /(R, R)$-DIOP catalyst system (Scheme 9). The stereoselectivity was found to be influenced by the structures of the chiral phosphine ligands and by those of the substrates, as well as by the reaction conditions. Moderate-to-good enanotioselectivities (up to $89 \%$ ee) were obtained, performing the reaction under an atmosphere of CO gas (400 psi) at $110^{\circ} \mathrm{C}$.

In 2019, Liao and co-workers developed a more general and selective method for the catalytic asymmetric thiocarbonylation of simple styrenes relying on $\mathrm{CO}$ gas and thiols as substrates (Scheme 10) [24]. Key to the success of this reaction was the use of chiral sulfoxide-(P-dialkyl)phosphine (SOP) ligands, which were developed in the authors' laboratory [25]. A broad range of highly enantioenriched thioesters (with up to $96 \%$ ee) was prepared in good-to-excellent yields under mild reaction conditions. The results of DFT calculations indicated that the Re-face attack
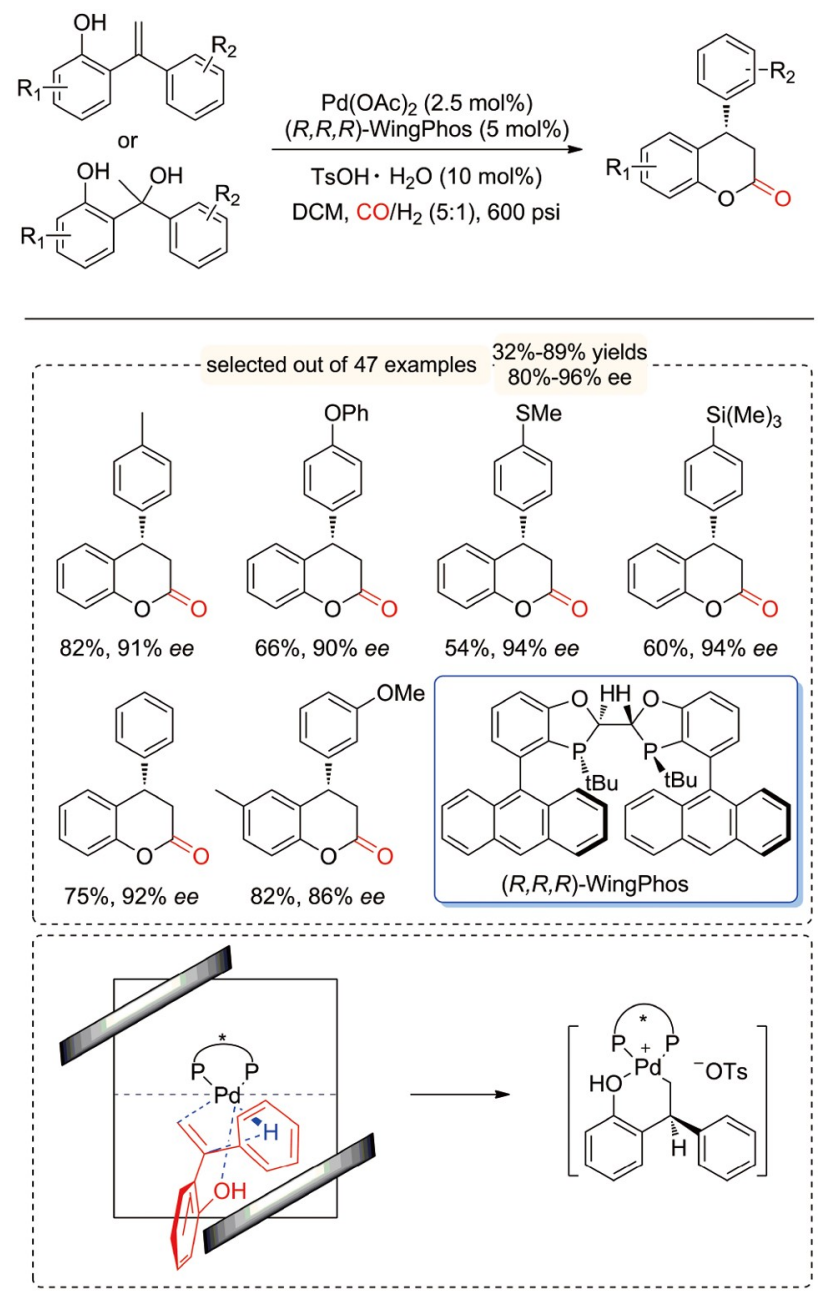

Scheme 8 Pd-catalyzed hydroesterification of 1,1-diaryl olefins and diarylmethyl carbinols (color online). 

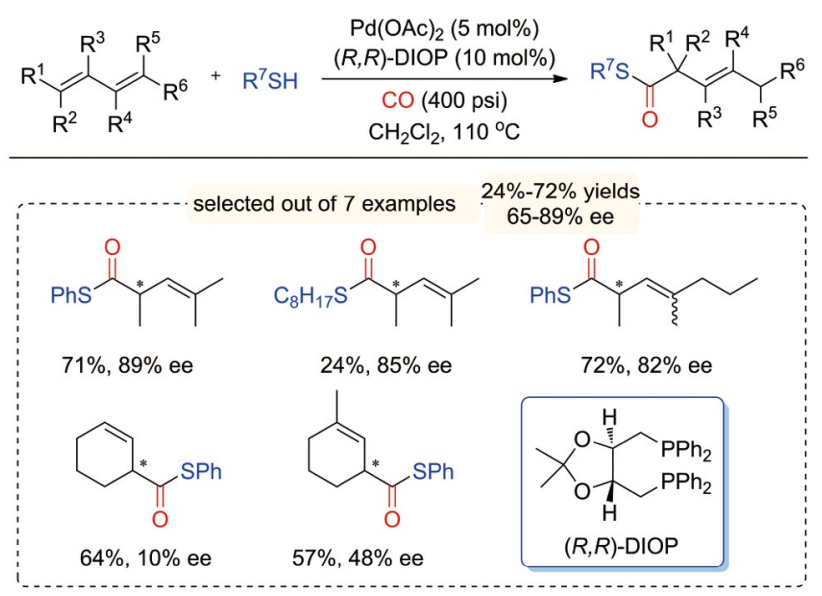

Scheme 9 Pd-catalyzed thiocarbonylation of 1,3-dienes (color online).
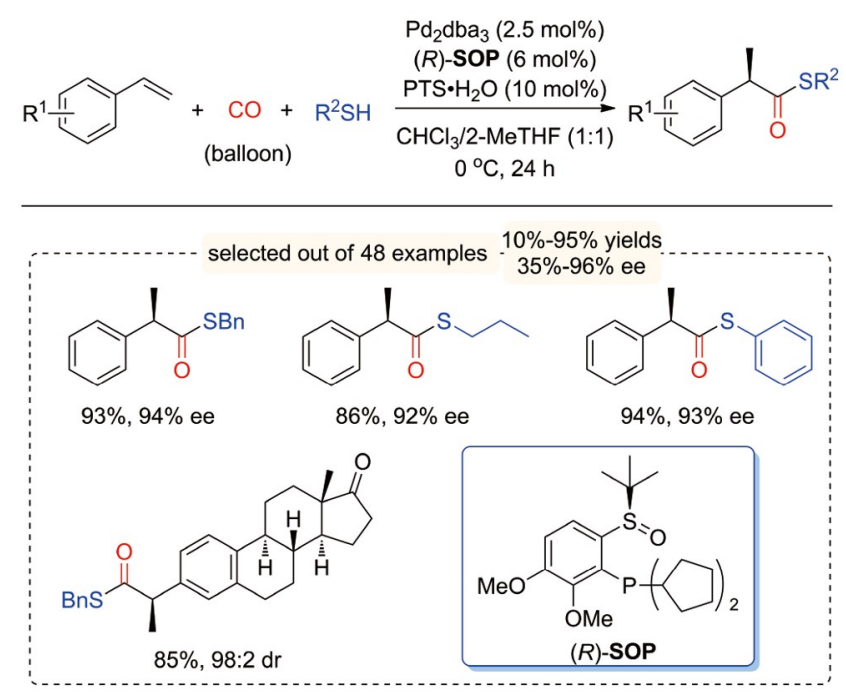

Scheme 10 Pd-catalyzed thiocarbonylation of styrenes (color online).

of Pd-H to styrene $\left(\Delta G_{\text {sol }}=13.7 \mathrm{kcal} \mathrm{mol}^{-1}\right)$ is thermodynamically favored over the Si-face attack of $\mathrm{Pd}-\mathrm{H}$ to styrene $\left(\Delta G \mathrm{sol}=15.7 \mathrm{kcal} \mathrm{mol}^{-1}\right.$, for a free energy difference of $2 \mathrm{kcal} \mathrm{mol}^{-1}$ between the two reactions).

\subsection{Palladium-catalyzed hydroaminocarbonylations}

Among alkene hydrocarbonylation reactions, hydroalkoxycarbonylations and hydrothiocarbonylations have been extensively developed. On the other hand, hydroaminocarbonylations, which are a promising approach to accessing linear or branched amides, have been explored to a far lesser extent. Recently, transition metal-catalyzed, ligand-controlled regiodivergent hydroaminocarbonylations have been established by several groups [26]. In general, the use of bidentate ligands is beneficial to the formation of linear amides via anti-Markovnikov hydroaminocarbonylations; by contrast, monodentate ligands favor Markovnikov hydroaminocarbonylations that yield branched amides. Recently, Guan and co-workers [27] developed a Pd-catalyzed asymmetric Markovnikov hydroaminocarbonylation of alkenes that relies on a $\mathrm{PdI}_{2}$-phosphoramidite catalytic system (Scheme 11). Indeed, a phosphoramidite ligand was used that afforded high reactivity and selectivity. The reaction course exhibited excellent regioselectivity and enantioselectivity in the reaction with alkenylarenes. Various 2-substituted propanamides were synthesized in high yields with up to $95 \%$ ee. Although aliphatic alkenes were also tolerated as reactants, when they were used, only low branched-to-linear (b/l) ratios and ee values were obtained. This observation might have resulted from the lack of functional groups that can bind or interact with the catalyst, as well as the small differentiation between the two prochiral faces of aliphatic alkenes. The results of mechanistic studies indicated that the reaction proceeds through a palladiumhydride pathway, and the hydropalladation is the regio-determining and enantio-determining step.

\section{Palladium-catalyzed carbonylative difunctio- nalization of alkenes}

\subsection{Palladium-catalyzed oxycarbonylations}

Tietze and co-workers [28] developed an enantioselective alkoxypalladation/carbonylation process for the synthesis of chromane structures and employed it in these authors' total synthesis of 4-dehydroxydiversonol (Scheme 12). In this case, a combination of Pd(OTFA $)_{2}$ and chiral $(S, S)$-BnBOXAX ligand was used to convert a phenolic compound into a chromane derivative in $80 \%$ yield and $96 \%$ ee. The chromane product was then converted to 4-dehydroxydiversonol in eight steps. This enantioselective dominoWacker/carbonylation/methoxylation process was then applied to the total synthesis of a series of related chromanones: (-)-blennolide A [29], (-)-diversonol [30], (-)-blennolide C, (-)-gonytolide C [31], and others [32].

Optically pure $\beta$-hydroxy alkylcarboxylic acids and relevant esters are widely represented among natural products and drugs, and they are also important synthons in synthetic chemistry. The oxycarbonylation of alkenes is one of the most concise and efficient methods for their synthesis. However, this strategy is mainly limited to intramolecular reactions; in fact, the intermolecular asymmetric oxocarbonylation of alkenes has not been solved until recently. In 2016, Liu's group [33] developed a Pd-catalyzed intermolecular oxocarbonylation of alkenes employing a hypervalent iodine reagent. Using the $\mathrm{Pd}(\mathrm{OAc})_{2} / \mathrm{PhI}(\mathrm{OAc})_{2} /$ $\mathrm{BF}_{3} \cdot \mathrm{Et}_{2} \mathrm{O}$ catalyst system, $\beta$-oxycarboxylic acids were synthesized from simple alkenes under a $\mathrm{CO}$ atmosphere (1 atm) at room temperature. In recent years, the said group found that the introduction of a steric blocking group at the C-6 


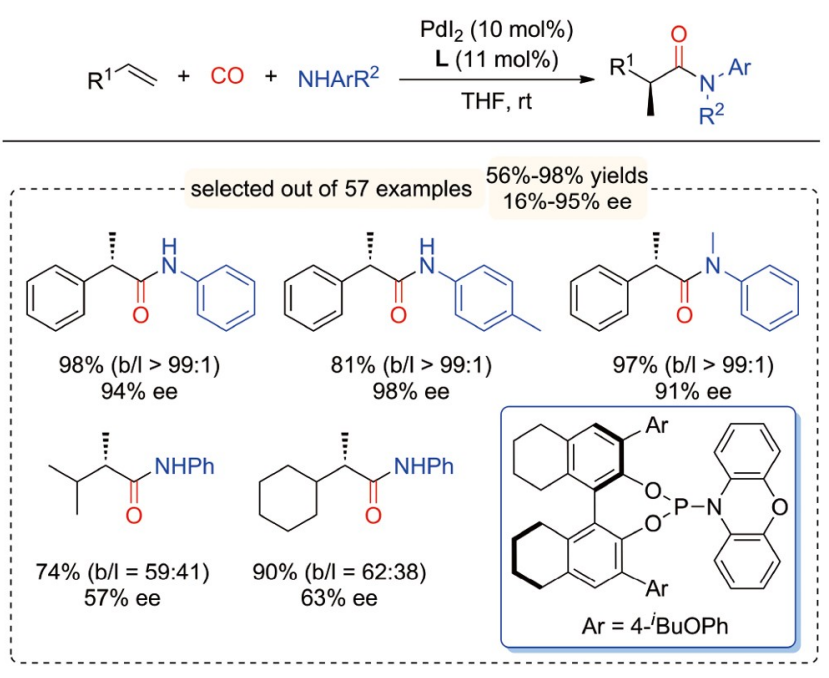

Scheme 11 Pd-catalyzed asymmetric markovnikov hydroaminocarbonylation of alkenes (color online).
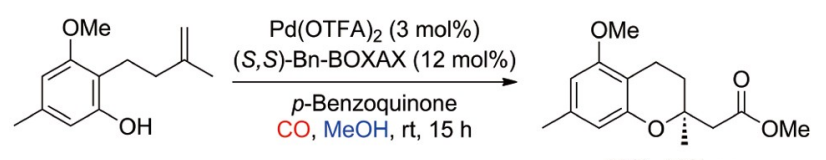

$80 \%, 96 \%$ ee

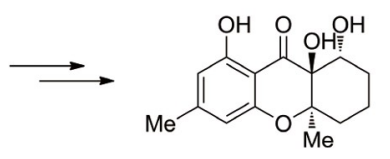

4-Dehydroxydiversonol

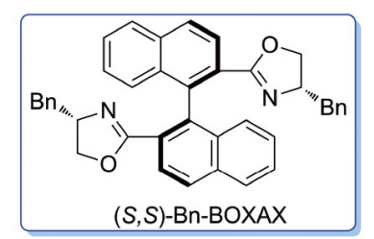

Scheme 12 Pd-catalyzed carbonylative process for the synthesis of chromane (color online).

pyridine position in chiral pyridine oxazoline (Pyox) ligands can significantly improve the electrophilicity of palladium catalysts; based on this finding, a series of efficient intramolecular asymmetric difunctionalization reactions of olefins were developed [34]. Recently, the same group realized the intermolecular asymmetric oxocarbonylation of olefins based on the chiral Pyox ligand, which they had developed; these researchers thus achieved excellent regioselectivity and enantioselectivity (Scheme 13) [35]. This synthetic route features mild reaction conditions, broad alkene substrate scope, and insensitivities to air and water; it provides a useful and direct route for the synthesis of chiral $\beta$-hydroxy alkylcarboxylic acids/esters. The key to this reaction is to introduce a substituent at the pyridine C- 6 position of the chiral ligand Pyox to increase the electrophilicity of the palladium catalysts and promote the initial enantioselective intermolecular oxypalladation. The generated alkyl-Pd species undergoes a carbonylation reaction to produce the relevant $\beta$-hydroxy alkylcarboxylic acid (Scheme 13, bottom left). In addition, by employing this

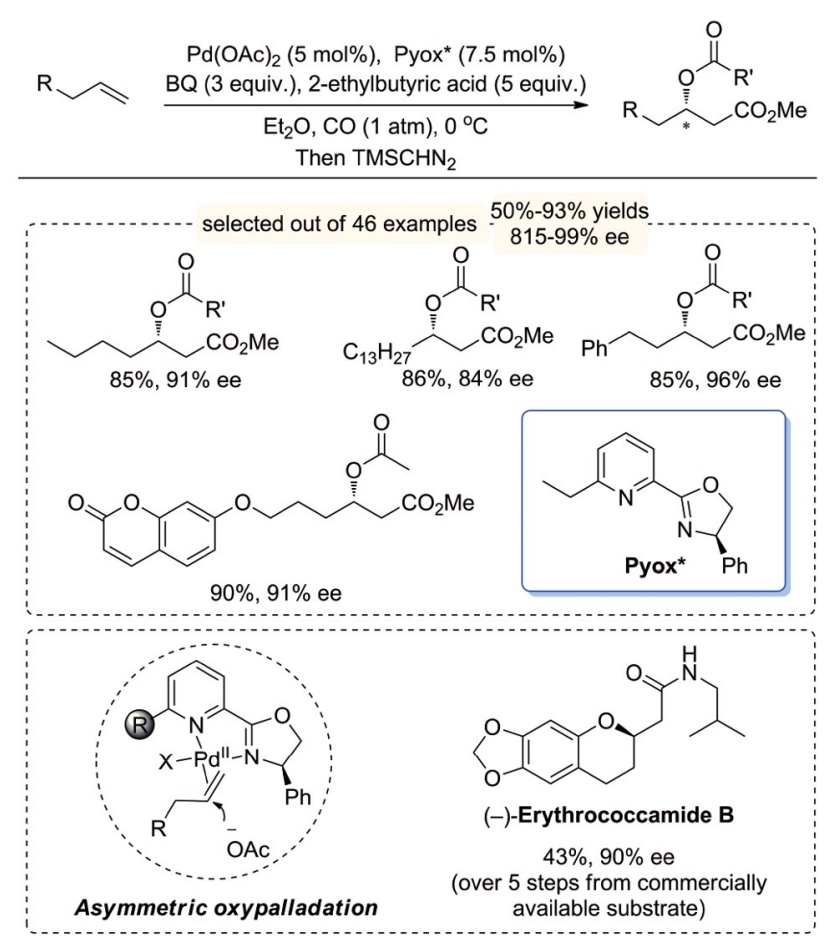

Scheme 13 Pd-catalyzed asymmetric oxocarbonylation of olefins (color online).

carbonylation reaction as the key step, the asymmetric synthesis of the biologically active natural product (-)-erythrococcamide B was completed in five steps, with a total yield of $43 \%$ and $90 \%$ ee, from commercially available materials (Scheme 13, bottom right).

\subsection{Palladium-catalyzed aminocarbonylations}

The enantioselective tandem transformation of allenes holds promise for the rapid construction of chiral complex molecules. A typical mode of transition metal-catalyzed allene functionalization involves the insertion of an allene into an $\mathrm{R}-\mathrm{M}$ bond to generate a transient $\pi$-allyl-M species that is trapped by an external or internal nucleophile, thus providing functionalized alkenes or cyclic compounds [36]. In 2015, Wang, Ding, and co-workers [37] reported a Pd-catalyzed enantioselective alkoxycarbonylation-amination cascade reaction involving terminal allenes, $\mathrm{CO}$, methanol, and arylamines as reactants (Scheme 14). An aromatic spiroketalbased diphosphine (SKP), which was developed by Ding's group [38] and afforded excellent control of the regioselectivity and enantioselectivity in a series of transformations, was used as a chiral ligand, and copper propionate $[\mathrm{Cu}$ $\left.(\mathrm{OCOEt})_{2}\right]$ was used as an oxidant to afford $\alpha$-methylene- $\beta$ arylamino acid esters under mild conditions (room temperature, ambient pressure CO). A series of $\alpha$-methylene- $\beta$ arylamino acid esters were obtained in good yields, excellent enantioselectivities (up to $96 \%$ ee), and high regioselec- 


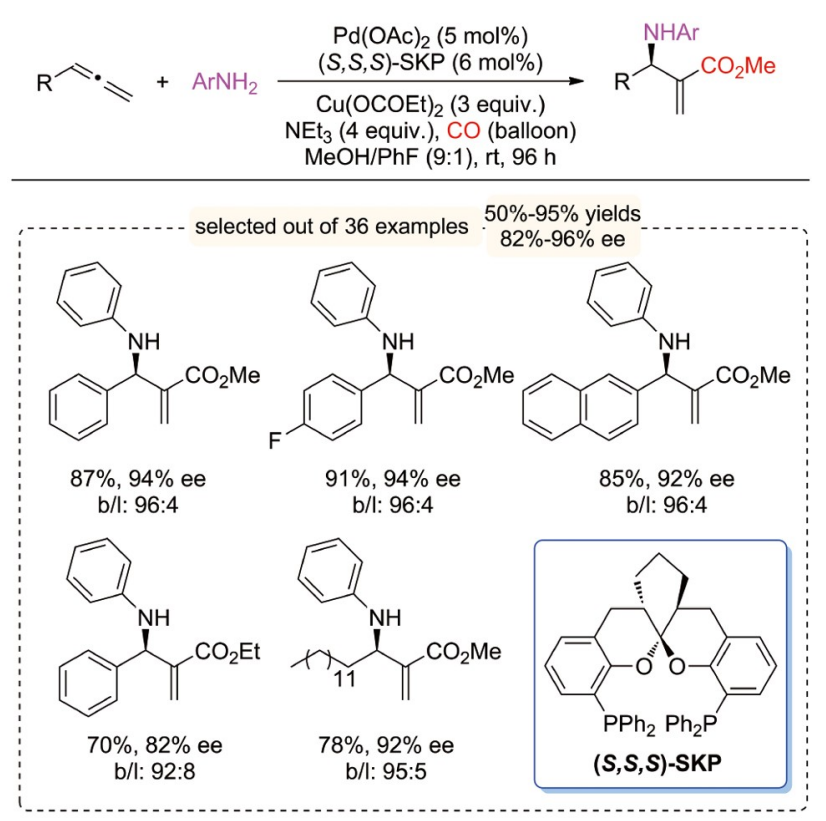

Scheme 14 Pd-catalyzed alkoxycarbonylation-amination of terminal allenes (color online).

tivities $(b / 1>92: 8)$. Results of the investigation of the reaction mechanism suggested that the reaction is likely to proceed through a cascade alkoxycarbonylpalladation of the allene followed by an amination process.

\subsection{Palladium-catalyzed bis-alkoxycarbonylations}

The oxidative bis-alkoxycarbonylation of olefins in the presence of alcohols to afford dialkyl succinates was developed as early as the 1970s [39]. The first asymmetric bisalkoxycarbonylation reaction was reported by Consiglio and co-workers [40] in 1992. In their initial study, the complex $\left[\mathrm{Pd}\left((R, R)-(\mathrm{DIOP})\left(\mathrm{O}_{2} \mathrm{CCF}_{3}\right)_{2}\right]\right.$ was used as the catalyst precursor in the presence of $\mathrm{Sn}(\mathrm{OTf})_{2}$; however, by this approach, low yield and low selectivity could only be achieved: $(R)$-dimethyl phenylsuccinate was isolated in $29 \%$ yield with $30 \%$ ee. Soon after, the same research group employed atropisomeric diphosphine ligands in the presence of $p$ $\mathrm{TsOH}$ for this reaction; in this case, high enantioselectivity (93\% ee) was obtained when styrene was used as the substrate [41]. However, the chemoselectivity of this reaction was low: $p$-hydroxyphenyl methyl 2-phenylsuccinate, monocarbonylated cinnamate, and some oligomers containing two terminal methoxycarbonyl groups were obtained as the main by-products. In 2003, Chan and co-workers [42] used palladium complexes comprising chiral dipyridylphosphines in the asymmetric bis-methoxycarbonylation of styrene; under optimal conditions, up to $84 \%$ ee enantioselectivity and $79 \%$ chemoselectivity were achieved (Scheme 15). The chemoselectivity of aliphatic olefins was lower than that of styrene, owing to multiple olefin insertions. In 2001, Ukaji and In-

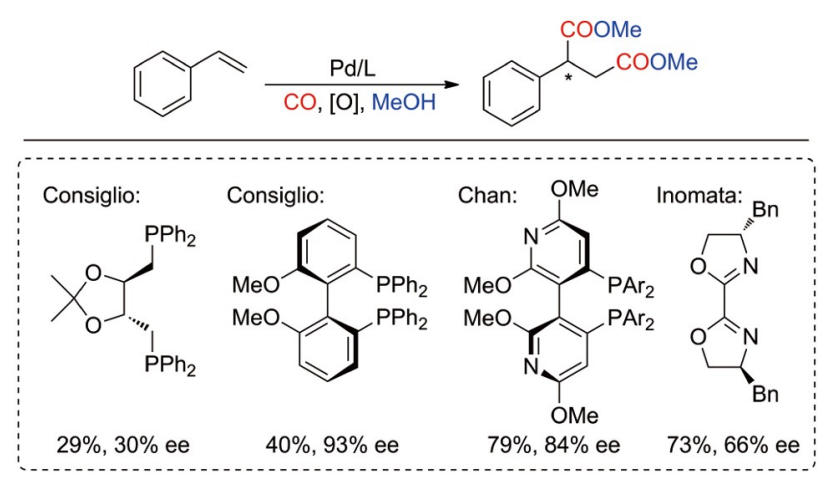

Scheme 15 Palladium-catalyzed asymmetric bis-alkoxycarbonylations (color online).

omata [43] developed a palladium-catalyzed asymmetric bisalkoxycarbonylation of terminal olefins that relied on a chiral bioxazoline ligand. The corresponding dimethyl-2phenylsuccinate was produced in $73 \%$ yield with a value for the enantioselectivity up to $66 \%$ ee. This palladium-bioxazoline system could also be employed in the asymmetric bis(alkoxycarbonylation) reaction of 1,2-dihydronaphthalenes and related cyclic olefins to give the corresponding optically active cis-dicarboxylates with enantioselectivity values up to $94 \%$ ee.

Thioureas have emerged as an important class of ligands for transition metal-catalyzed reactions, owing to their high air stability and ease of electronic tuning. The Yang group [44] developed a series of carbonylative transformations catalyzed by $\mathrm{Pd}$-thiourea complexes and performed them under a balloon pressure of CO. In 2007, Marder, Chen, Yang, and co-workers [45] designed a new class of chiral $S, N$-heterobidentate thiourea-oxazoline ligands that the said researchers employed in the Pd-catalyzed enantioselective bis-alkoxycarbonylation of terminal olefins (Scheme 16). By this approach, and using $\mathrm{CuCl}$ as a co-oxidant, terminal olefins were efficiently bisalkoxycarbonylated to the corresponding succinic diesters in excellent yields and moderate enantioselectivities under mild conditions. Notably, in this reaction scheme, the atropoisomerism at the $\mathrm{N}-\mathrm{C}_{\text {aryl }}$ bond played a more important role in determining enantioselectivity than the chiral oxazoline moiety. An $84 \%$ ee was obtained using the more robust anthracene-substituted bidentate thiourea-oxazoline $S, N$-ligand [46].

\subsection{Palladium-catalyzed heck carbonylations}

Transition metal-catalyzed tandem Heck/carbonylation reactions represent efficient methods to construct a variety of synthetically versatile carbonyl compounds from readily available organic halides and alkenes. Notably, this strategy has been applied in the convenient construction of polycyclic skeletons that are widely represented in natural products and bioactive molecules. Since the systematic work by Negishi et 

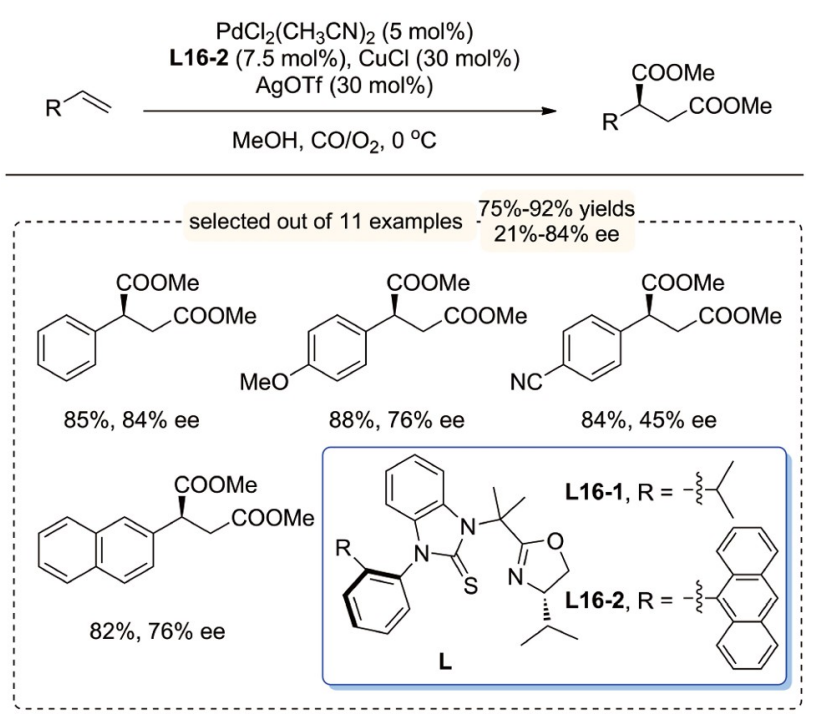

Scheme 16 Pd-catalyzed bis(methoxycarbonylation) of alkenes with an $S, N$-ligand (color online).

al. [47], the Pd-catalyzed carbonylative cyclization has been extensively studied, and it has been recognized as a powerful tool in the construction of cyclic ketones. In 1999, Hayashi and co-workers [48] established a catalyst system based on $\mathrm{Pd}\left(\mathrm{OCOCF}_{3}\right)_{2} /(S)$-BINAP to be utilized in the asymmetric carbonylative cyclization of prochiral $o$-allylaryl triflates and 2-allylalkenyl triflates with $\mathrm{CO}$ to produce chiral cyclopentenones (Scheme 17). High yields and enantioselectivities were obtained (up to $96 \%$ ee).

Although the Pd-catalyzed intramolecular asymmetric Heck carbonylation is an effective method for the construction of complex heterocyclic compounds bearing quaternary stereocenters, the enantioselective version of this transformation has rarely been reported until recently. This kind of reaction usually results in the formation of the key alkyl-Pd intermediate through the carbopalladation of olefins. One of the most important challenges to achieving enantioselectivity in these reactions is to control the $\beta$ elimination step, which might lead to the loss of the newly formed stereocenter. This type of reactivity could be intrinsically prohibited with the generation of an all-carbon quaternary stereogenic center, which lacks a $\beta-\mathrm{H}$ moiety available for elimination, thus ensuring that the subsequent transformations occur selectively. In 1998, Overman and coworkers [49] reported an example of cyclic carbopalladationcarbonylation (CCC) cascade reaction in their synthesis of the calabar bean alkaloids physostigmine and physovenine; however, the achieved enantioselectivity was not satisfactory. In recent years, with the development of versatile chiral ligands, several examples of enantioselective $\mathrm{CCC}$ tandem reactions have been reported. In 2018, Correia and coworkers [50] reported the first asymmetric Heck carbonylative Suzuki coupling and esterification reaction of arene-

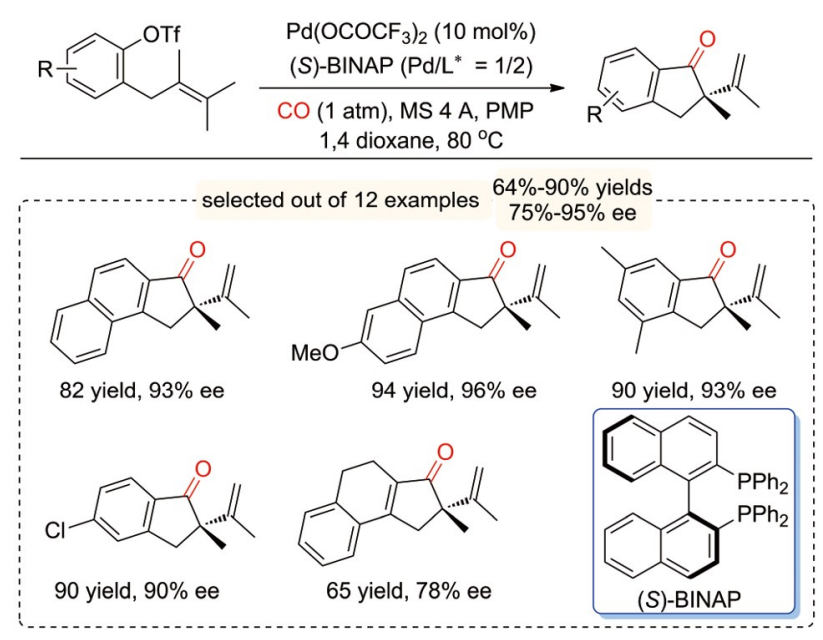

Scheme 17 Asymmetric carbonylative cyclization of allylaryl triflates (color online).

diazonium salts that yielded asymmetric dihydrobenzofurans containing a quaternary carbon center (Scheme 18). Using $\mathrm{Pd}(\mathrm{TFA})_{2}$ as the catalyst and bis(oxazoline) $((S)$-BOx $\mathbf{L})$ as the ligand, alkenyl-tethered aryldiazonium salts reacted with methanol (or boronic acids) under a balloon pressure of $\mathrm{CO}$ to give the desired products in good yields and up to $98: 2$ enantiomeric ratio (er). Based on the absolute configuration of the obtained products, the authors proposed that, after oxidative addition to the diazonium salt, alkene complexation to the cationic palladium species is the enantiodetermining step; notably, this complexation would occur preferentially through the Si-face of the olefin moiety in the transition state. The following carbopalladation led to the formation of $R$-configuration of the stereocenter (Scheme 18). $C O$ insertion into the $\sigma$-alkyl-palladium species and the subsequent nucleophilic substitution and reductive elimination lead to the formation of cyclic carbonyl products.

In 2019, Luo and Zhu [51] described an elegant Pd-catalyzed carbonylative Heck cyclization reaction of alkenyl substrates with embedded oxygen-based or nitrogen-based nucleophiles for the enantioselective construction of allcarbon spirooxindole $\gamma$-lactones/lactams and $\delta$-lactones/lactams (Scheme 19). Under a balloon pressure of CO, and in the presence of $\operatorname{Pd}_{2}(\mathrm{dba})_{3}$ and an axially chiral bidentate phosphine ligand $\left(\left(R_{a}\right)\right.$-L19), branched alcohol/amine-substituted $N$-(2-iodophenyl)- $N$-methylacrylamides underwent intramolecular carbopalladation and carbonylative lactonization to produce spirooxindole $\delta$-lactones/lactams or $\gamma$ lactones/lactams in $51 \%-99 \%$ yields and $67 \%-99 \%$ ee. Notably, the $(S)$-enantiomer of the $\gamma$-lactone could also be prepared with excellent enantioselectivity using $\left(S_{a}\right)$-L19 as the palladium ligand. This reaction exhibited good functional group tolerance, and it has been implemented as a key step in the syntheses of the natural product coixspirolactam A and of an effective CRTH2 receptor antagonist. Indeed, They pro- 


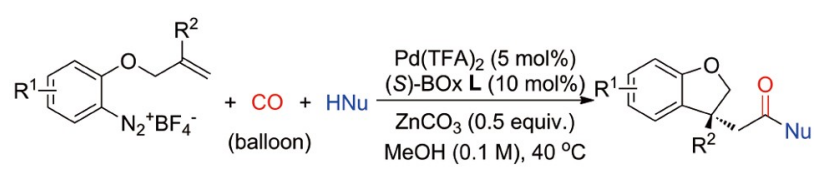

$\mathrm{HNu}=\mathrm{MeOH}, \mathrm{ArB}(\mathrm{OH})_{2}$

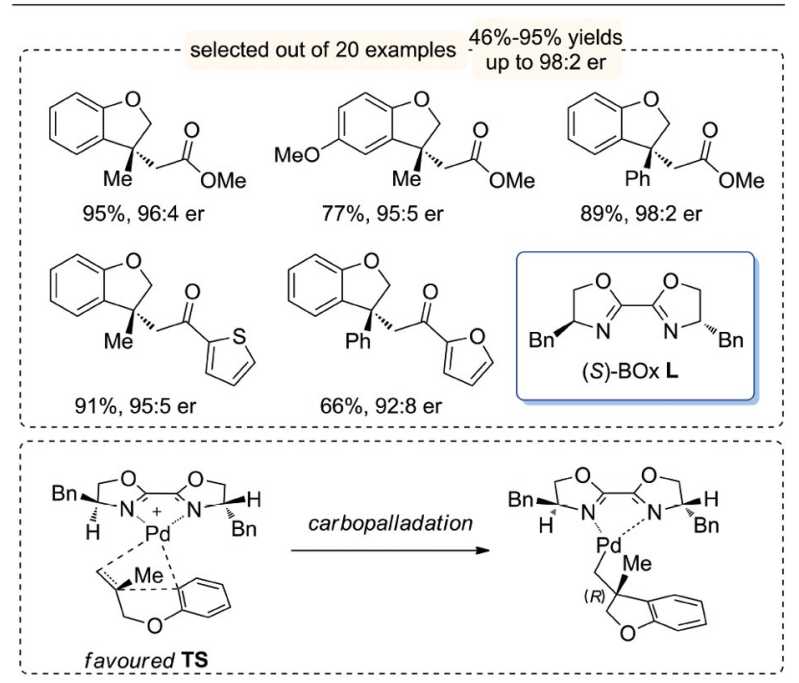

Scheme 18 Enantioselective intramolecular heck carbonylation reactions (color online).

posed a transition state for this reaction to explain the asymmetric introducing (Scheme 19, bottom left). The species obtained as a result of the coordination of the terminal alkene to the $\mathrm{Pd}^{\mathrm{II}}$ center in the aryl-Pd intermediate should adopt a configuration where the side-chain is stretched to the open area away from ligand to avoid the strong steric repulsion (Scheme 19, bottom right). Subsequently, migratory insertion of the alkenyl moiety to $\mathrm{Ar}-\mathrm{Pd}^{\mathrm{II}}$ followed by $\mathrm{CO}$ insertion and nucleophilic cyclization afforded either spirooxindole lactones or lactams with an $R$-configuration.

In 2020, Lin and Yao et al. [52] reported a Pd-catalyzed asymmetric tandem Heck/carbonylation desymmetrization of cyclopentenes that produced bicyclo[3.2.1]-octanes, which are found in several bioactive natural products. Employing $\mathrm{Pd}_{2}(\mathrm{dba})_{3} \cdot \mathrm{CHCl}_{3}$ (or $\left.\mathrm{Pd}(\mathrm{dba})_{2}\right)$ as the catalyst and (S)-difluorphos as the ligand, various chiral bicyclo[3.2.1] octane products bearing one all-carbon quaternary and two tertiary carbon stereogenic centers were synthesized in 50\%$98 \%$ yields and $88 \%-97 \%$ ee. The formation of two diastereomeric intermediates was proposed to explain the observed stereochemical outcome of the reaction (Scheme 20, bottom). With the C2-symmetric (S)-configured ligand, the right transition state is unfavorable due to the steric repulsion between the benzoyl moiety of the cyclopentene and the benzene ring of the ligand.

In 2020, Guan and co-workers [53] reported the monodentate ligand-assisted highly enantioselective Pd-catalyzed domino Heck carbonylation reaction (Scheme 21). A new monodentate phosphoramidite ligand, Xida-Phos, was developed for this reaction, and its use afforded good reactivity
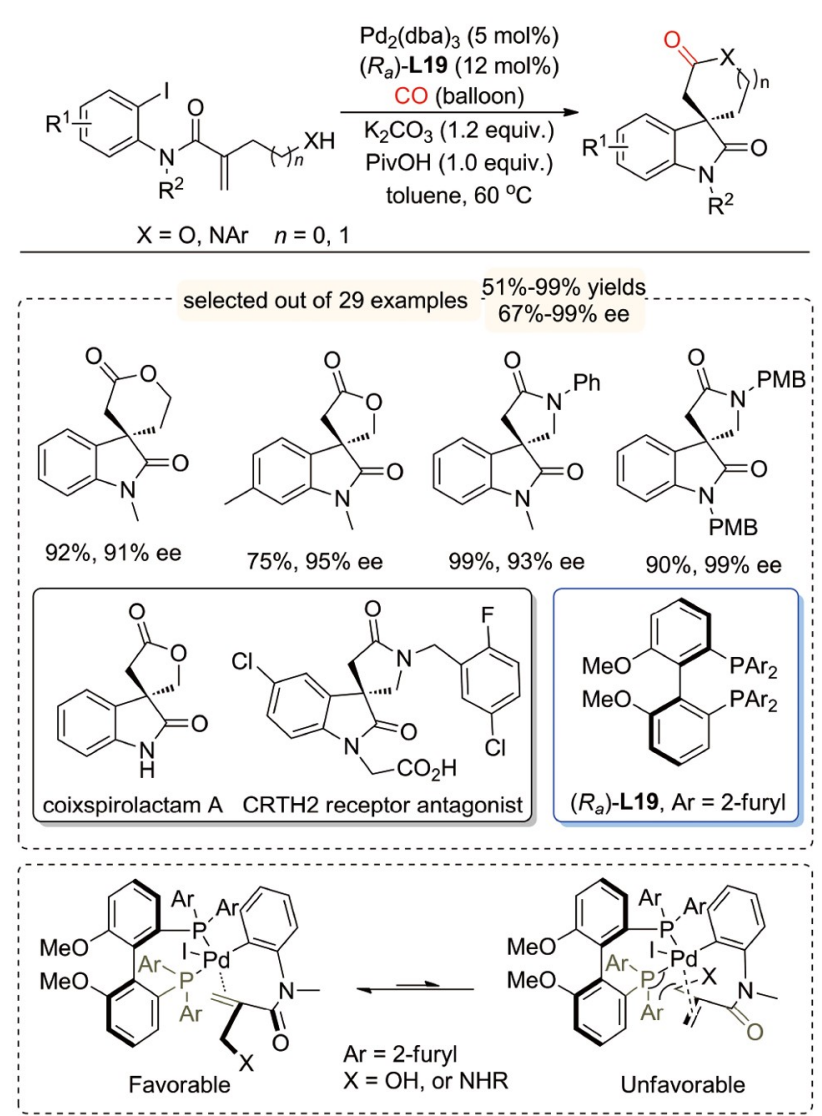

Scheme 19 Enantioselective heck/carbonylative cyclization (color online).

and enantioselectivity. A wide range of oxindoles bearing $\beta$ carbonyl-substituted all-carbon quaternary stereocenters was obtained at $85 \%-97 \%$ ee and in $50 \%-91 \%$ yields. Various nucleophiles, including arylboronic acids, anilines, and alcohols, were tolerated in this reaction. Notably, no reaction was observed to take place when commonly used bidentate ligands, including BINAP, DIOP, and Box, were used. The authors proposed that a monodentate ligand can facilitate the transmetalation of the arylboronic acid to $\mathrm{Pd}$ via a $\mathrm{Pd}-\mathrm{O}-\mathrm{B}$ intermediate [54]. The stoichiometric reaction revealed that the Pd-complex INT-1 is a key intermediate in the reaction. Notably, the competition between $\mathrm{CO}$ and the ligand for the coordination of the Pd center leads to an erosion of the reaction's enantioselectivity. Importantly, this methodology was also applied to the formal synthesis of the bioactive hexahydropyrroloindole (HPI) alkaloids (+)-physostigmine, $(+)$-physovenine, and $(+)$-phenserine, as well as to the asymmetric total synthesis of dimeric HPI alkaloid (+)-folicanthine.

In addition to the formation of five-membered rings, the intramolecular Heck/carbonylation reaction has also been implemented to realize six-membered cyclization reactions. In 2019, the Zhang group [55] reported a Pd-catalyzed intramolecular Heck/carbonylation reaction for the en- 

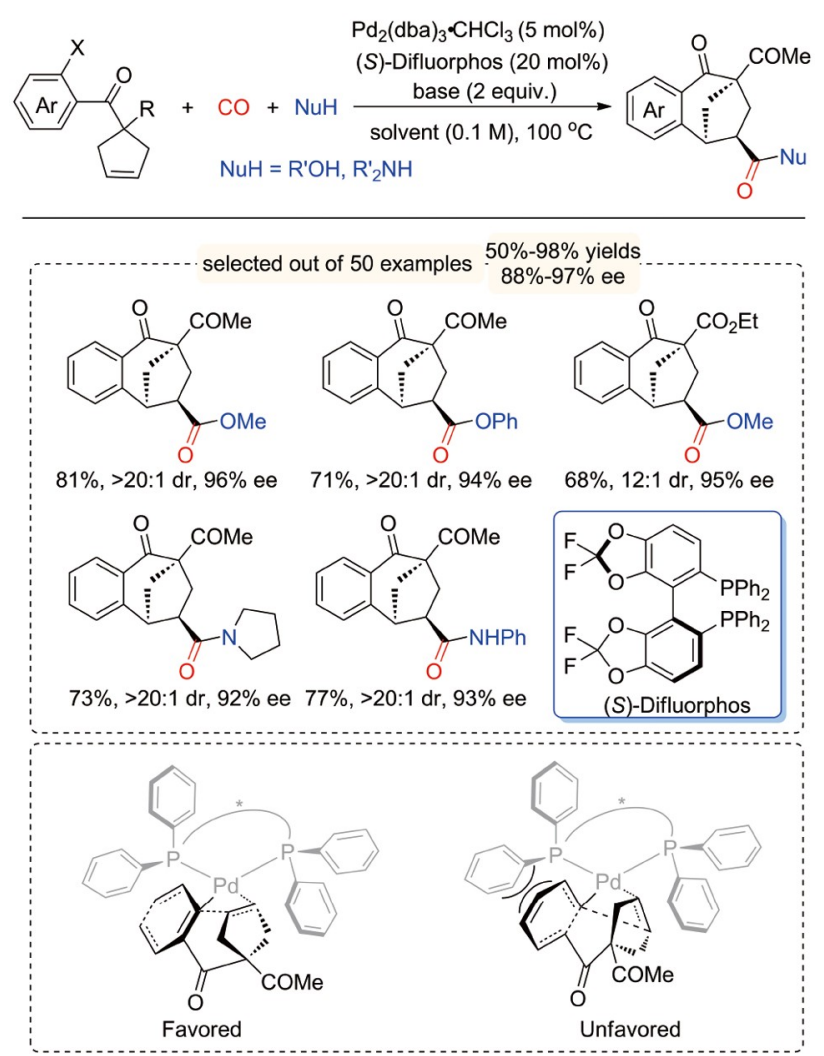

Scheme 20 Tandem heck/carbonylation desymmetrization of cyclopentenes (color online).

antioselective synthesis of quaternary 3,4-dihydroisoq- uinolines (Scheme 22). Aryl formates were used as commercially available and low-toxicity sources of CO [56]. Using $(R)$-SEGPHOS as the ligand, a range of isoquinolinones bearing all-carbon quaternary centers were prepared via $\mathrm{Pd}$ catalysis starting from the corresponding $N$-allyl benzamides in good yields and high enantioselectivities. A mechanism was proposed for this reaction, whereby the enantioselectivities were introduced into the intramolecular carbopalladation of aryl-Pd ${ }^{\mathrm{II}}$ species and alkenes to produce the alkyl$\mathrm{Pd}^{\mathrm{II}}$ intermediate reported in the bottom section of Scheme 22.

Intramolecular asymmetric Heck carbonylation reactions have been reported to be applied in the construction of fivemembered and six-membered rings; however, the construction of seven-membered rings by this strategy has rarely been reported. Recently, Zhu and Luo et al. [57] have reported the Pd-catalyzed asymmetric 7-exo-trig Heck carbonylation cascade reaction as a way to synthesize seven-membered dibenzo[b,d]azepin-6-ones (Scheme 23). Importantly, the main challenge in the construction of seven-membered rings via the Heck carbonylation route consists in the fact that the direct carbonylation of the aryl-Pd intermediate in advance of alkene insertion is likely to occur when the alkene is far away from the Pd center; this reactivity would, in turn, constitute a side-reaction that severely affects the yield of the
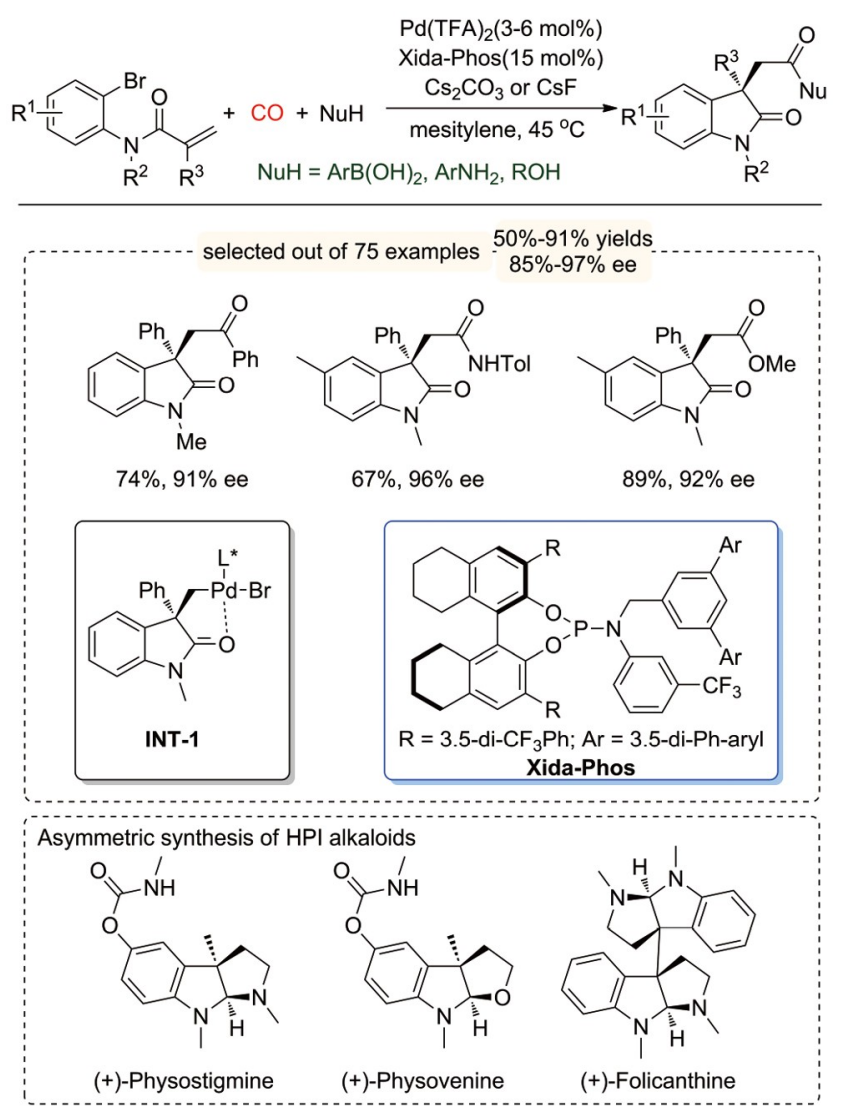

Scheme 21 Monodentate ligand-assisted pd-catalyzed heck carbonylation reaction (color online).

desired products. In order to address this problem, the said authors designed as the reaction substrate $N-\left(2^{\prime}\right.$-iodo-[1, $1^{\prime}$ biphenyl]-2-yl)-acrylamide, which contains a rigid biaryl backbone. Using a chiral cyclic phosphine as ligand, a series of 7-acetate-substituted or 7-acetamide-substituted dibenzo $[\mathrm{b}, \mathrm{d}]$ azepin-6-ones were generated in good yields and $86 \%$ $97 \%$ ee. Both alcohols/phenols and anilines could serve as nucleophiles in the described reaction scheme. DFT calculation results indicate that the chiral axis of the bridged arylazazodone skeleton is controlled by the newly formed chiral center on the ring. The author proposed a transition state that introduces asymmetry: after oxidative addition of aryl iodide to $\operatorname{Pd}(0)$, the terminal alkene would approach the $\mathrm{Pd}(\mathrm{II})$ center from the orientation away of the ligand (Scheme 23, bottom, left).

\section{Palladium-catalyzed carbonylation of alkynes, allenes, and enynes}

\subsection{Palladium-catalyzed carbonylation of alkynes}

In its total synthesis of kallolides A and B [58], the Marshall group [59] developed an efficient conversion reaction of propargylic mesylate to allenic ester through a Pd-catalyzed 

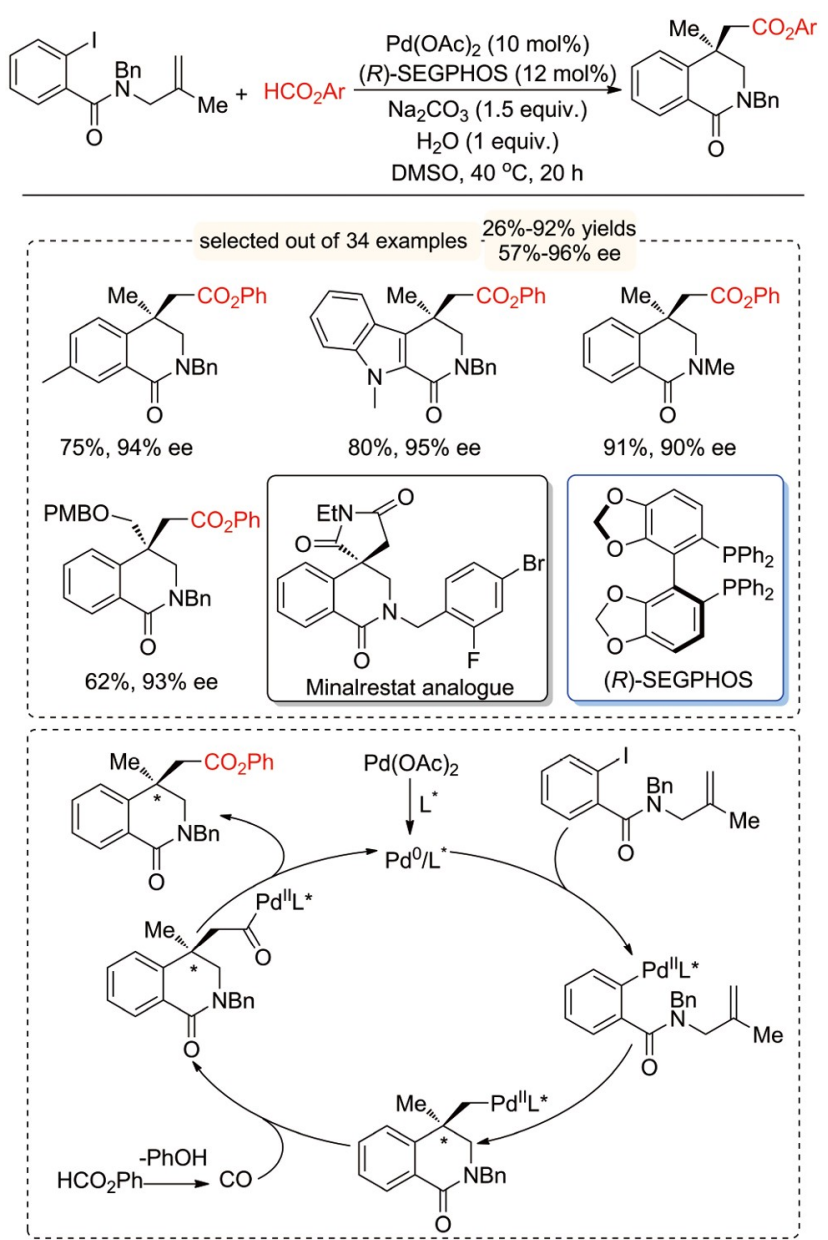

Scheme 22 Pd-catalyzed heck/carbonylation for the synthesis of isoquinolines (color online).

alkoxycarbonylation occurring with net inversion of configuration. Indeed, the conversion of the enantioenriched propargylic mesylates afforded the allenic esters with inversion of configuration through treatment with $\mathrm{CO}$ and alcohols under Pd catalysis. These reactions proceeded with about $10 \%$ racemization or less. In 2013, Wang and Ma [60] reported an improved procedure that relied on palladium catalysis and (S)-SEGPHOS as the ligand (Scheme 24). Notably, high efficiency of chirality transfer was achieved under mild reaction conditions. The configuration of allenoates was determined based on the stereochemistry of the substrates. When $(R)$-SEGPHOS was used as the ligand of palladium instead of (S)-SEGPHOS, the efficiency of the chirality transfer dropped slightly; in fact, the reaction was very slow due to the mismatching between the $(S)$-substrate and $(R)$-SEGPHOS.

In a report published in the same year, Ma et al. [61] described the catalytic asymmetric carbonylation of readily available racemic propargylic carbonates for the synthesis of optically active 2,3-allenoates (Scheme 25). The reaction represents an efficient method for the convenient and highly enantioselective formation of three-carbon axial chirality
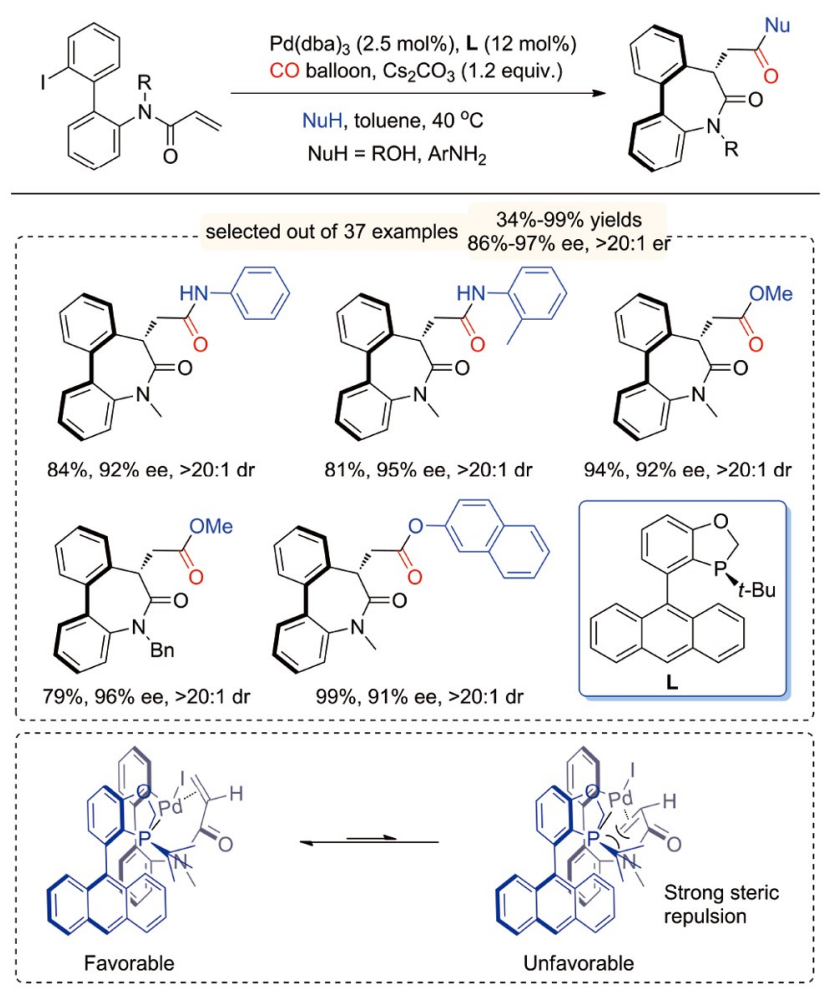

Scheme 23 Pd-catalyzed asymmetric 7-exo-trig heck carbonylation cascade reaction (color online).

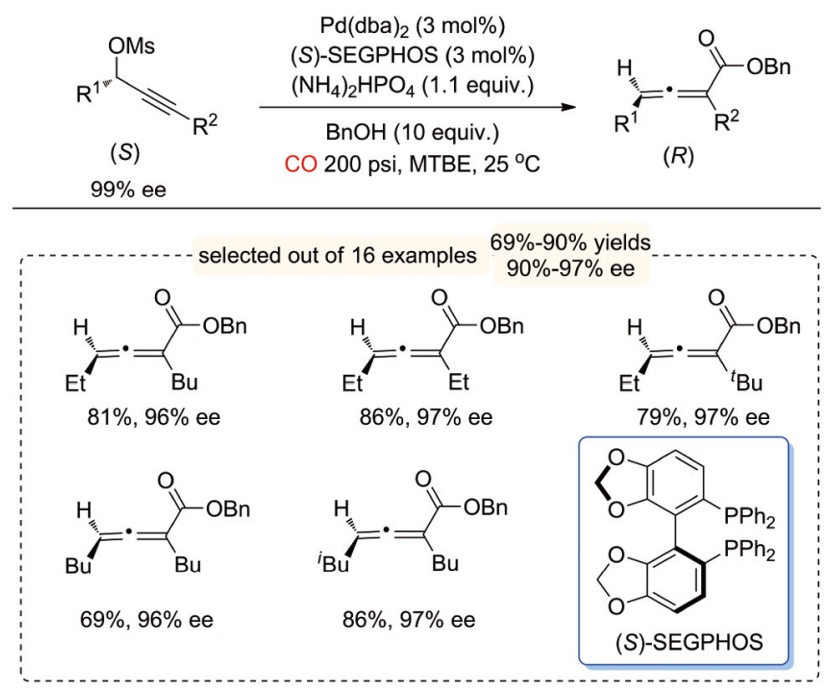

Scheme 24 Pd-catalyzed alkoxycarbonylation of enantioenriched propargylic mesylates (color online).

from readily available racemic propargylic carbonates bearing central chirality. [(R)-ECNU-Phos], a chiral bisphosphine ligand based on a biphenyl skeleton, was used as the ligand in combination with $[(\pi \text {-allyl }) \mathrm{PdCl}]_{2}$, as the catalyst. A series of chiral allenoates with different functionalities were produced with up to $97 \%$ ee. Moreover, evidence indicated that the presence of the 3,5-dimethoxy group in the ECNU-Phos may afford the required steric and 

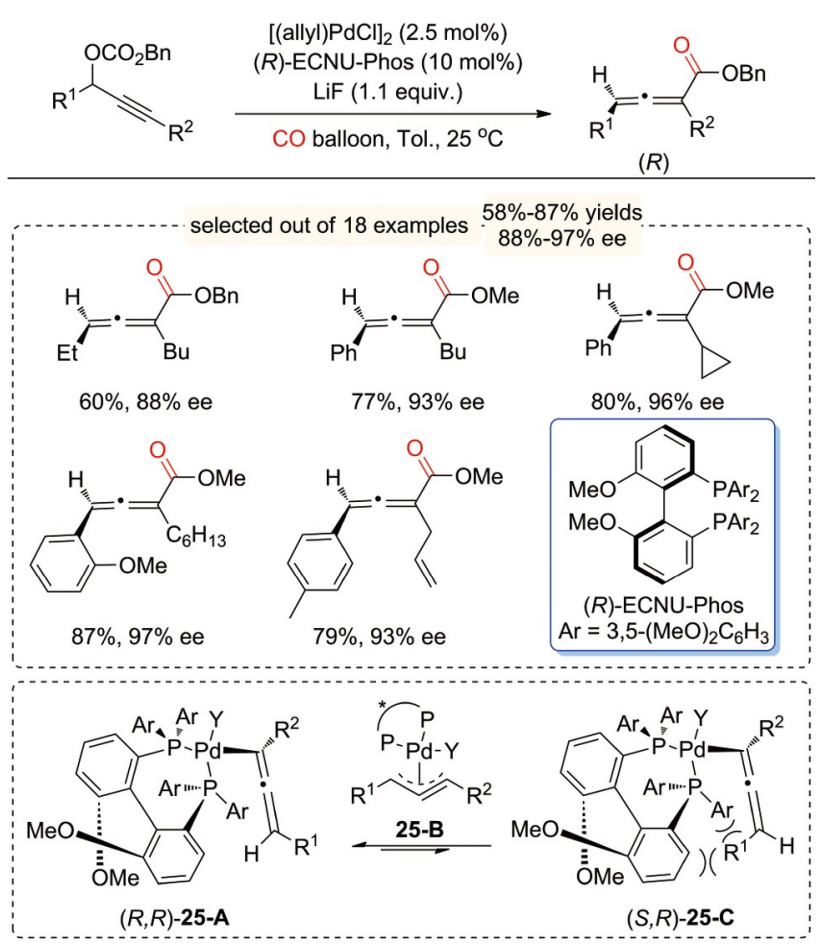

Scheme 25 Pd-catalyzed alkoxycarbonylation of racemic propargylic mesylates (color online).

electronic environment, and it may also be responsible for the reaction taking place already at mild temperatures, which is a critical feature of the system, given the temperature-sensitive nature of optically active allenes. Indeed, $\mathrm{Ma}$ and co-workers proposed a working model to predict the absolute configuration of the product (Scheme 25, bottom). After the oxidative addition of the Pd catalyst with the propargylic carbonates, both $(R)$-allenylpalladium and $(S)$-allenylpalladium species would be generated, which could isomerize into each other through $\sigma-\pi-\sigma$ rearrangement via the intermediacy of compound 25-B reported in Scheme 25. Structural analysis indicated that $(S, R)-\mathbf{2 5 - C}$ is disfavored due to the steric interaction between the R1 group and the biaryl skeleton and the $\operatorname{Ar}$ group of $(R)$ ECNU-Phos. Therefore, the allenoate with the $R$-configuration is formed as the product via the intermediacy of $(R$, $R)$-25-A with high enantioselectivity.

\subsection{Palladium-catalyzed carbonylation of allenes}

Recently, Dong et al. [62] reported a Pd-catalyzed asymmetric carbonylative Heck reaction taking place between $o$ iodoanilines and allenes that was aimed at the synthesis of chiral dihydroquinolinone derivatives (Scheme 26). Notably, $(R)$-BTFM-GarPhos was used as the ligand, and moderateto-good yields and selectivities were achieved. The er value could be improved to 99:1 through the recrystallization of the isolated products. The slow addition of $o$-iodoaniline to the

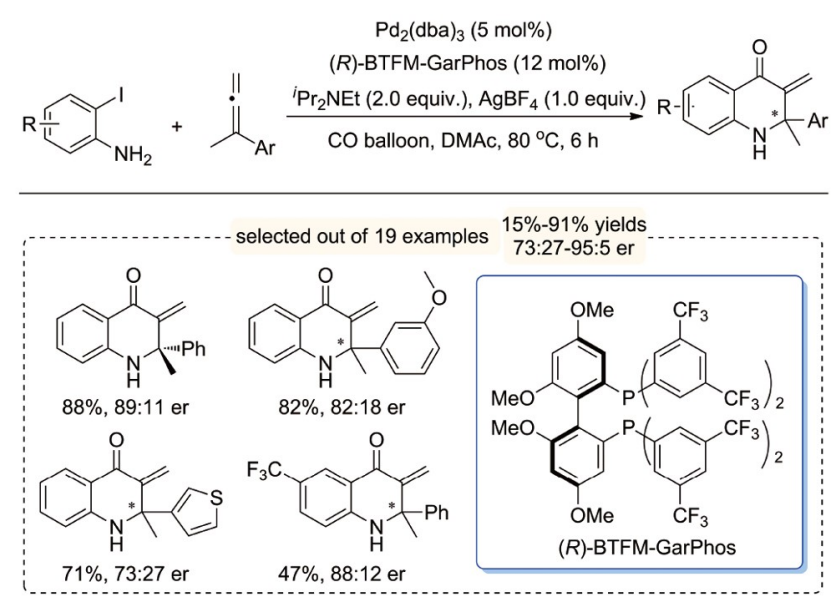

Scheme 26 Pd-catalyzed asymmetric carbonylative heck reaction between $o$-iodoanilines and allenes (color online).

reaction mixture by syringe pump was crucial to inhibiting the side reactions and improving the reaction's chemoselectivity.

Bäckvall's group [63] developed a series of Pd ${ }^{\mathrm{II}}$-catalyzed oxidative transformations of different types of allenes that take place under oxidative conditions. In 2015, this group [64] reported a highly efficient Pd-catalyzed oxidative cascade carbonylation-carbocyclization-carbonylation-alkynylation reaction of enallenes that resulted in the formation of four $\mathrm{C}-\mathrm{C}$ bonds (Scheme 27). With an efficient control of the chemoselectivity, this cascade reaction proceeded via the selective insertion of $\mathrm{CO}$, olefin, and $\mathrm{CO}$. Two years later, the same group reported the asymmetric variants of this cascade reaction. The main challenge of this asymmetric cascade reaction is the identification of suitable chiral catalyst systems since $\mathrm{CO}$ is a strong ligand of transition metals. Considering that the commonly used phosphine ligands are trend to degradation under oxidative conditions, whereas the use of a polydentate ligand would prevent the coordination of the olefin unit to the $\mathrm{Pd}^{\mathrm{II}}$ center, the authors selected chiral phosphoric acid as a suitable chiral source [65].

Using a pre-made Pd ${ }^{\mathrm{II}}$-VAPOL-PA phosphate complex as the catalyst system, a range of chiral cyclopentenones were conveniently synthesized in good yields with er values up to 95.5:4.5. A plausible mechanism for this asymmetric cascade reaction was proposed (Scheme 27, bottom). First, the coordination of enallene to $\mathrm{Pd}^{\mathrm{II}}$ produces intermediate 27-A, which in turn is transformed into carbonyl $\mathrm{Pd}^{\mathrm{II}}$ intermediate 27-B via allene attack and CO insertion. Subsequently, the enantioselective migratory insertion of the alkene into the $\mathrm{C}-$ $\mathrm{Pd}$ bond generates the carbocyclic intermediate 27-C. This step is believed to be the chirality-forming step that introduces the chiral center at the $\alpha$-position of the ketone. Finally, carbonylative alkynylation of intermediate 27-C yields the product and releases $\mathrm{Pd}^{0}$, which is re-oxidized to $\mathrm{Pd}^{\mathrm{II}}$ by $\mathrm{BQ}$ for the next catalytic cycle. 

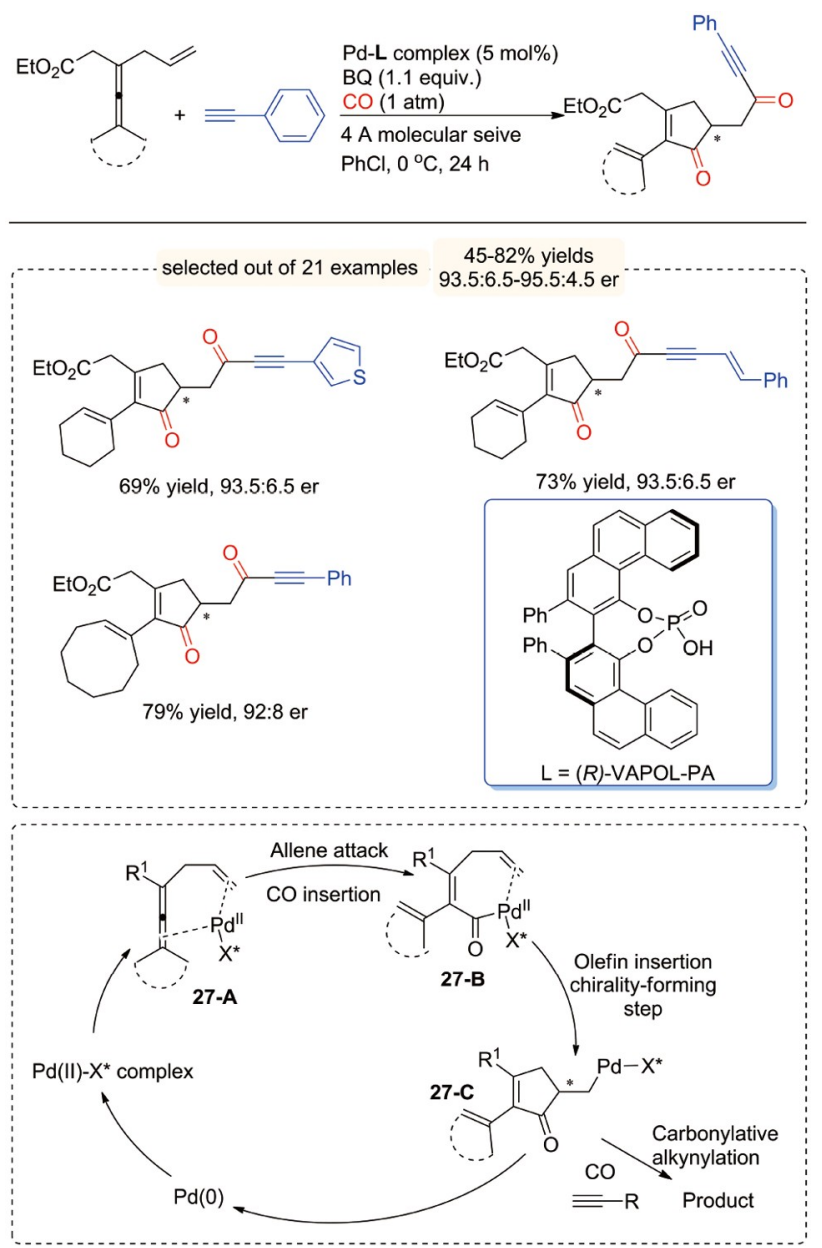

Scheme 27 Pd-catalyzed oxidative cascade carbonylation-carbocyclization-carbonylation-alkynylation reaction of enallenes (color online).

\subsection{Palladium-catalyzed carbonylation of enynes}

The transition metal-catalyzed stereoselective cyclization of 1,6-enynes provides efficient and convenient access to five-membered (hetero)cycles [66]. Recently, Dong and coworkers [67] developed a Pd-catalyzed enantioselective hydroesterification-cyclization reaction of amide-tethered 1,6-enynes (Scheme 28). Using as catalyst system the combination of $\mathrm{Pd}(\mathrm{OAc})_{2}, \quad(S)$-MeOBIPHEP, and $\mathrm{TsOH} \cdot \mathrm{H}_{2} \mathrm{O}$, a series of chiral carboxylic esters containing the $\gamma$-lactam skeleton and an all-carbon quaternary carbon stereocenter were synthesized with $69 \%-95 \%$ ee values for the enantioselectivity. The mentioned reaction is initiated by the formation of palladium hydride, which is followed by the addition of the alkyne group to produce an alkenylpalladium intermediate. Subsequently, intramolecular insertion of the alkene unit into the alkenyl-palladium intermediate generates a metal-alkyl complex comprising a quaternary carbon stereocenter. Afterward, $\mathrm{CO}$ insertion and a nucleophilic attack of alcohol yield the chiral $\gamma$-lactam products.
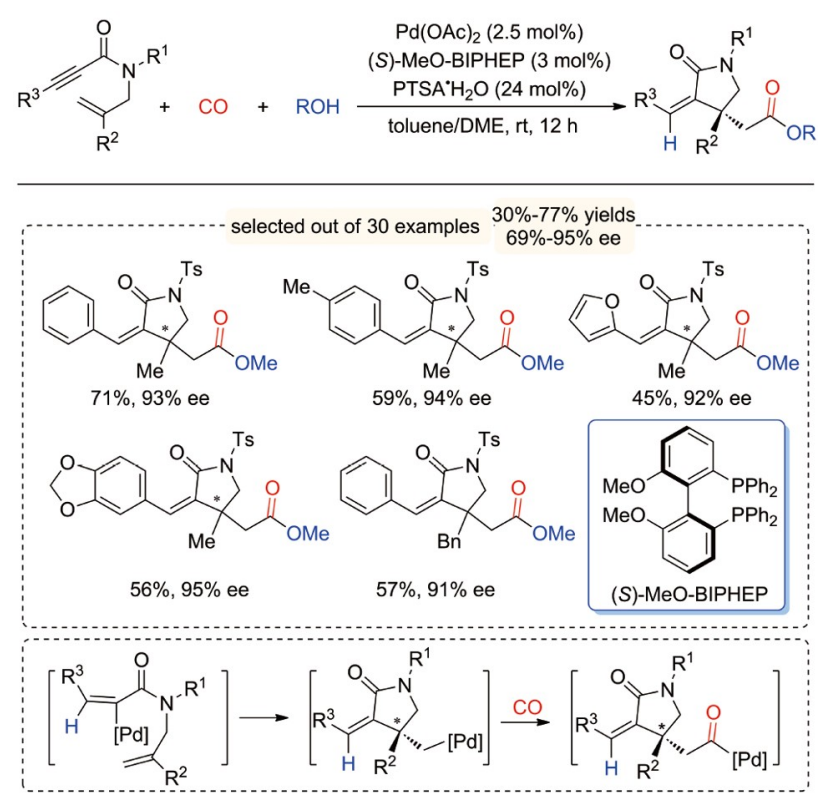

Scheme 28 Pd-catalyzed enantioselective hydroesterification-cyclization of 1,6-enynes (color online).

\section{Palladium-catalyzed asymmetric $\mathbf{C}-\mathbf{H}$ activation/carbonylation}

\subsection{Palladium-catalyzed asymmetric $\mathrm{C}\left(\mathrm{sp}^{2}\right)-\mathrm{H}$ activation/carbonylation}

With the significant development of transition metal-catalyzed asymmetric $\mathrm{C}-\mathrm{H}$ bond activation, the desymmetrization of prochiral molecules comprising a prochiral quaternary carbon has attracted a great deal of research interest. In 2019, Xu and co-workers [68] reported a $\mathrm{Pd} / \mathrm{Cu}-$ cocatalyzed enantioselective desymmetric $\mathrm{C}-\mathrm{H}$ carbonylation of diarylsulfonamide performed as part of the synthesis of chiral isoindolinone and isoquinolinone cores (Scheme 29). Mono- $N$-protected amino acids (MPAAs) [69] were used as palladium ligands in this reaction. Under balloon pressure of a $\mathrm{CO} / \mathrm{O}_{2}$ gas mixture, lactam-type products isoindoline-1-ones and isoquinoline-1-ones were prepared in $50 \%-94 \%$ yields and $81 \%-96 \%$ ee. Both the mono- $N$-protected amino and acid moieties were found to be essential to the reactivity, and they were observed to play important roles in determining the reaction's enantioselectivity. Results of DFT calculations indicated that the reaction proceeded via an enantioselective carbamoyl-Pd-oriented $\mathrm{C}-\mathrm{H}$ activation mechanism.

Nearly at the same time, Xia and co-workers [70] reported their $\mathrm{Pd}$-catalyzed enantioselective $\mathrm{C}-\mathrm{H}$ carbonylation by desymmetrization conducted employing commercially available $L$-pyroglutamic acid as a chiral ligand (Scheme 30). Reaction systems based on ligands that were subjected to $N$-substitutions with alkyl and benzyl groups exhibited good reactivity and produced chiral isoquinolinones in good yields and high enantioselectivities under mild conditions. 

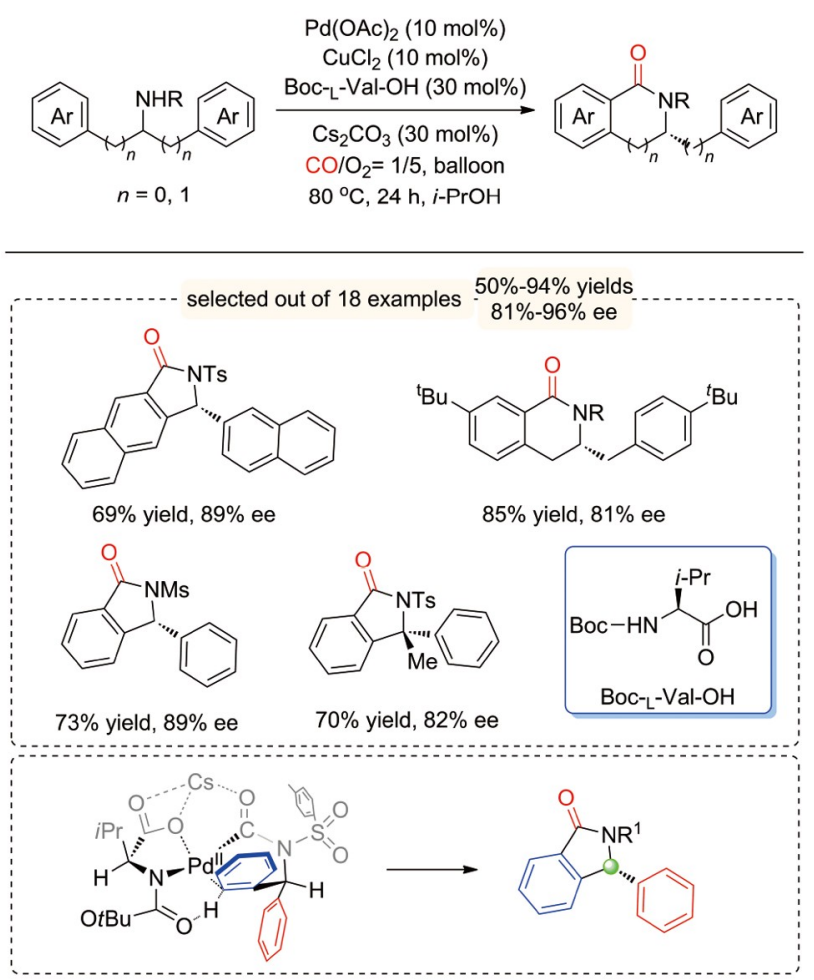

Scheme $29 \mathrm{Pd} / \mathrm{Cu}$-cocatalyzed enantioselective desymmetric $\mathrm{C}-\mathrm{H}$ carbonylation (color online).

Mechanistic studies and DFT calculations indicated that $\mathrm{C}-\mathrm{H}$ activation is involved in the reaction's rate-determining step. Following Pd(II) center coordination by the amino group, the $\mathrm{C}-\mathrm{H}$ bond cleavage would take place at the ortho-position of either pro- $R$ or pro- $S$ phenyls via the transition states 30-ts-R (bottom, right, Scheme 30) or 30-ts-S (bottom, left, Scheme 30 ), respectively. Notably, the energy barrier to the formation of the transition state 30-ts-S was calculated to have a value of $16.9 \mathrm{kcal} / \mathrm{mol}$, while that to the formation of the transition state 30-ts-R was calculated to have a value of $17.9 \mathrm{kcal} / \mathrm{mol}$, which is $1.0 \mathrm{kcal} / \mathrm{mol}$ higher than its counterpart for 30-ts-S formation. Therefore, compounds exhibiting $S$-configurations at the stereogenic centers were obtained as the major products.

Later, Wang and co-workers [71] reported a Pd(II)-catalyzed asymmetric $\mathrm{C}\left(\mathrm{sp}^{2}\right)-\mathrm{H}$ activation/aminocarbonylation of $\mathrm{N}$-alkoxy-2,2-diarylpropanamides for the synthesis of 6membered azacycles bearing an all-carbon quaternary stereogenic center (Scheme 31). The use of mono- $N$-protected$\alpha$-amino- $O$-methylhydroxamic acid (Cbz-2-Nal-NHOMe) ligand did not simply promote reactivity under mild conditions, but it also provided high levels of stereoinduction. Indeed, a series of isoquinoline-1,3(2H,4H)-diones were obtained in good yields with $75 \%-93 \%$ ee. Notably, counteranions acetylacetonate and acetate were found to play key roles also in reactivity enhancement.

Very recently, Bai, $\mathrm{Xu}$, and co-workers [72] reported an
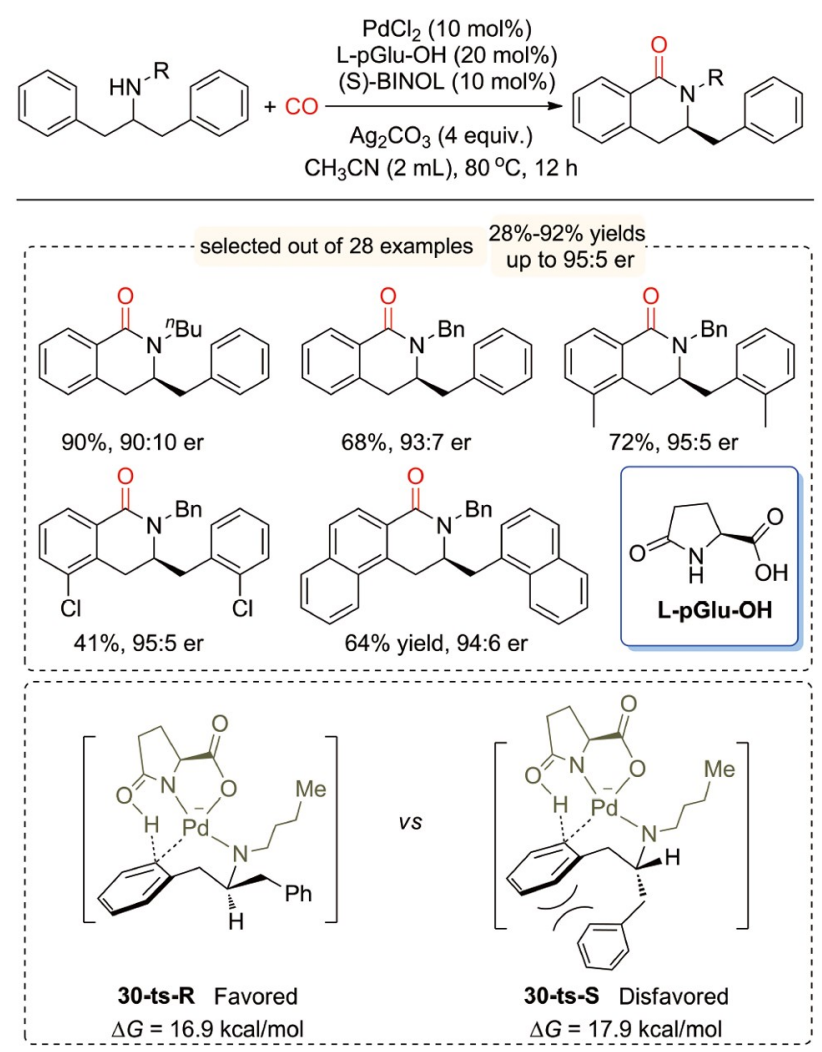

Scheme 30 Pd-catalyzed enantioselective desymmetric C-H carbonylation (color online).
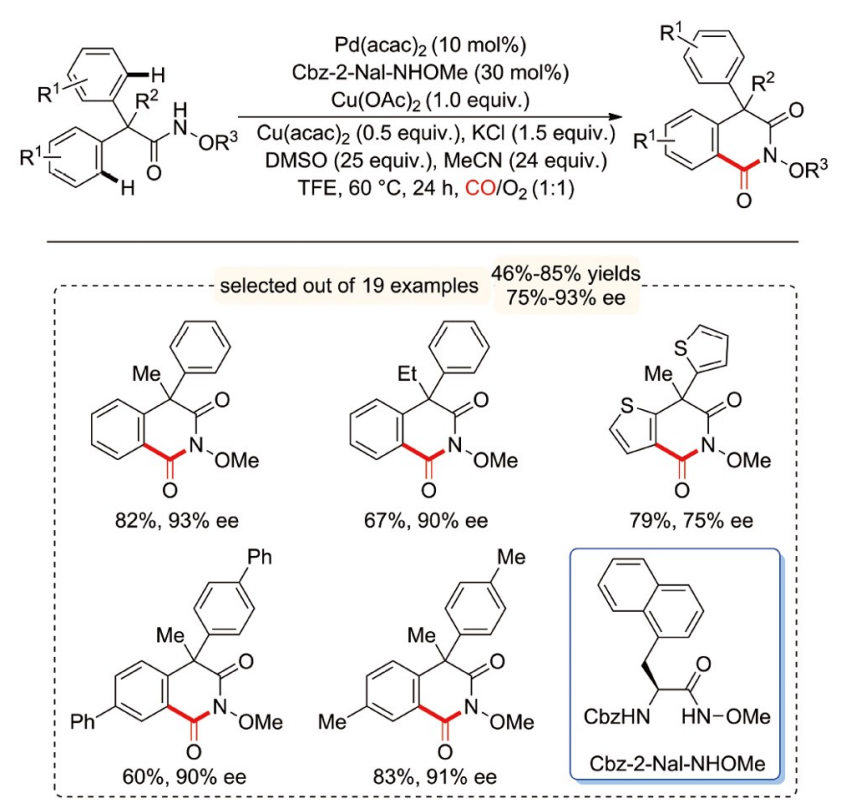

Scheme 31 Pd-catalyzed asymmetric $\mathrm{C}\left(\mathrm{sp}^{2}\right)-\mathrm{H}$ activation/aminocarbonylation of $N$-alkoxy-2,2-diarylpropanamides (color online).

enantioselective kinetic resolution of sterically hindered benzylamines performed through a transition metal-catalyzed oxidative carbonylation reaction (Scheme 32). Relying on $\mathrm{Pd} / \mathrm{Cu}$-cocatalysis in the presence of the chiral amino acid 


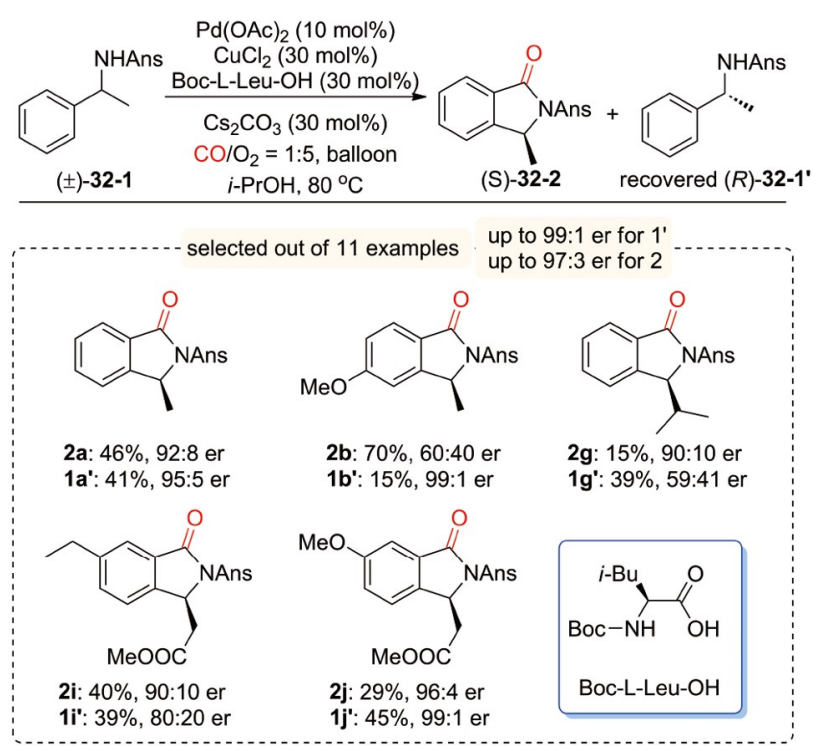

Scheme 32 Enantioselective kinetic resolution of sterically hindered benzylamines (color online).

ligand Boc-L-Leu-OH, the enantioselective $\mathrm{C}-\mathrm{H}$ activation/ amine carbonylation of sterically hindered benzylamines afforded the production of chiral isoindolinones (er up to 97:3). The origin of the chemoselectivity and stereoselectivity of this kinetic resolution reaction was elucidated by performing DFT calculations.

In 2017, Baudoin and co-workers [73] developed the Pdcatalyzed $\mathrm{C}\left(\mathrm{sp}^{3}\right)-\mathrm{H}$ carbamoylation of readily accessible carbamoyl chlorides for the synthesis of valuable $\beta$-lactams (Scheme 33). An enantioselective version of this reaction had been developed that made use of a TADDOL-derived chiral phosphonite ligand.

The Tang group [74] reported an enantioselective Pd-catalyzed $\mathrm{C}\left(\mathrm{sp}^{2}\right)-\mathrm{H}$ carbamoylation of diarylmethyl carbamoyl chlorides as part of the synthesis of chiral isoindolines (Scheme 34). Using chiral monophosphorus compound $(R)$ AntPhos as the ligand, a series of chiral isoindolines were prepared in good yields and with excellent enantioselectivities. Notably, CO addition did not just inhibit the decarbonylation side-reaction, but it also improved enantioselectivity.

\subsection{Palladium-catalyzed asymmetric $\mathrm{C}\left(\mathrm{sp}^{3}\right)-\mathrm{H}$ activation/carbonylation}

$\mathrm{C}\left(\mathrm{sp}^{3}\right)-\mathrm{H}$ carbonylations are much more challenging to realize than the $\mathrm{C}\left(\mathrm{sp}^{2}\right)-\mathrm{H}$ activation/carbonylation reactions [75], and most of them largely rely on DG-based strategies. In this context, extensive studies have been conducted on the design of preinstalled or transient DGs on account of their ability to accelerate cyclometalation and suppress $\beta$-hydride elimination. In 2020, Zhuang and Yu [76] reported the Pdcatalyzed enantioselective $\mathrm{C}\left(\mathrm{sp}^{3}\right)-\mathrm{H}$ functionalization of

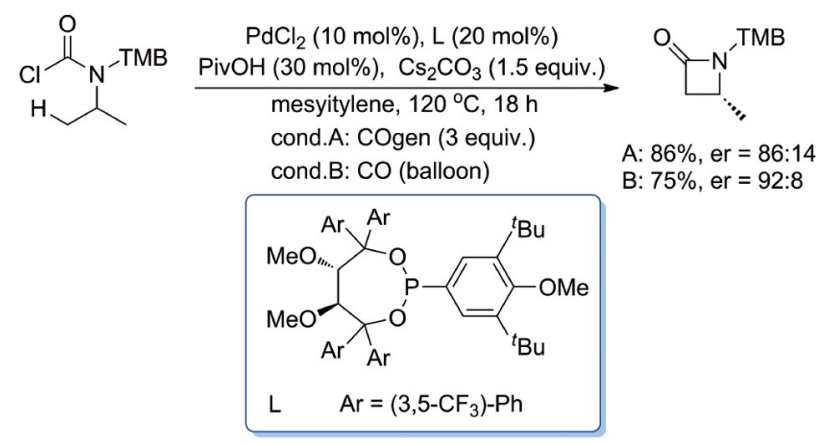

Scheme 33 Pd-catalyzed $\mathrm{C}\left(\mathrm{sp}^{3}\right)-\mathrm{H}$ carbamoylation of carbamoyl chlorides (color online).
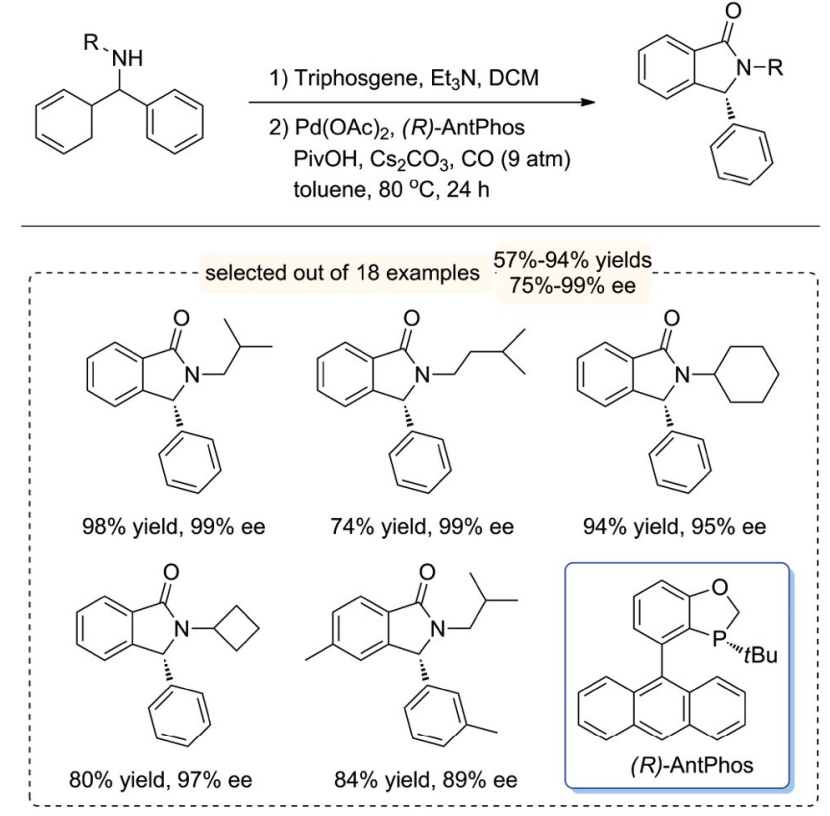

Scheme 34 Pd-catalyzed $\mathrm{C}\left(\mathrm{sp}^{2}\right)-\mathrm{H}$ carbamoylation of diarylmethyl carbamoyl chlorides (color online).

cyclopropylmethylamines that relied on a chiral bidentate thioether ligand (Scheme 35). Notably, the bidentate coordination mode and thioether motif of this ligand favor the generation of the requisite mono(amine)-Pd(II) intermediate, thus enabling the enantioselective $\mathrm{C}-\mathrm{H}$ activation of free amines. The use of this Pd/thioether catalyst system was extended to the enantioselective carbonylation of free primary and secondary aliphatic amines. Using $\mathrm{Mo}(\mathrm{CO})_{6}$ as a nonhazardous and air-stable solid source of $\mathrm{CO}$, several cyclopropane-fused pyrrolidones were prepared in moderate yields $(33 \%-63 \%)$ with good enantioselectivities (up to 97:3 er).

Recently, Yu and co-workers [77] reported the $\beta-\mathrm{C}\left(\mathrm{sp}^{3}\right)-\mathrm{H}$ or $\gamma-\mathrm{C}\left(\mathrm{sp}^{3}\right)-\mathrm{H}$ carbonylation of free carboxylic acids achieved employing a similar strategy (Scheme 36). The enantioselective carbonylation of free cyclopropanecarboxylic acids was also achieved using a chiral bidentate thioether ligand. Indeed, the introduction of a methyl group 


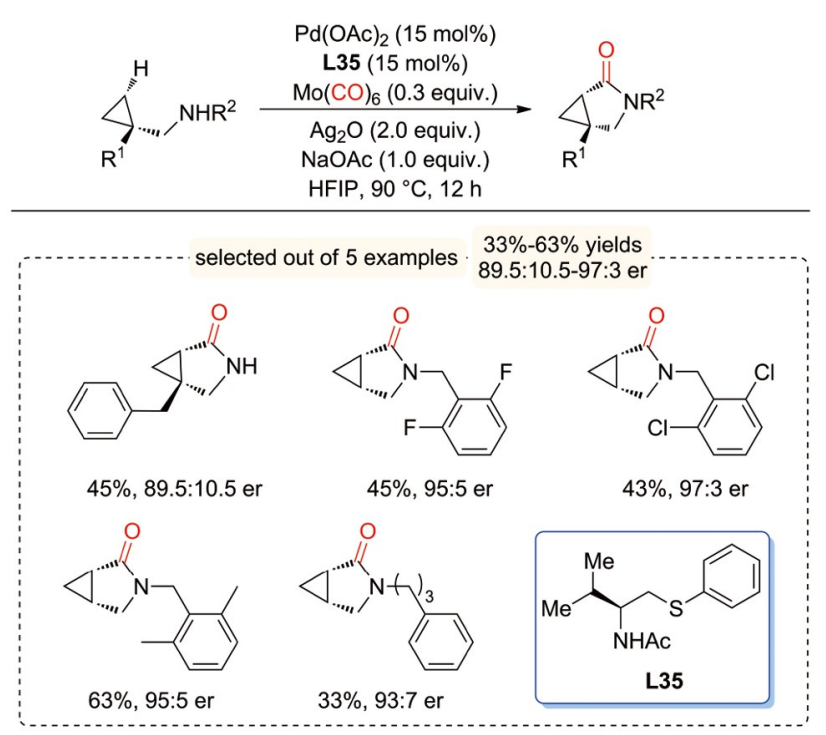

Scheme 35 Pd-catalyzed enantioselective $\mathrm{C}\left(\mathrm{sp}^{3}\right)-\mathrm{H}$ functionalization of cyclopropylmethylamines (color online).

in the backbone of the bidentate thioether ligand was found to play an important role in reactivity and enantioselectivity. The mentioned authors were able to successfully convert several cyclopropanecarboxylic acids to cyclopropane-fused succinic anhydrides with good enantioselectivities (up to $96: 4$ er) and moderate yields $(36 \%-60 \%)$.

\section{Other palladium-catalyzed asymmetric carbonylations}

Recently, Pd-catalyzed carbonylation reactions have also been employed in $\alpha$-arylation reactions implemented for the construction of stereogenic quaternary carbons [78]. Tang and co-workers [79] developed the enantioselective $\alpha$-carbonylative arylation for the production of chiral spirocyclic $\beta, \beta^{\prime}$-diketones. Good yields and high enantioselectivities (up to $96 \%$ ee) were achieved when $\operatorname{Pd}_{2}(\mathrm{dba})_{3}$ was used as the catalyst and an ethylene-bridged chiral bisphospholane, $((R$, $R)$-Ph-BPE), was used as ligand. From a mechanistic viewpoint, an acyl-palladium complex (compound 37-B in Scheme 37) is generated after oxidative addition and $\mathrm{CO}$ insertion via intermediate 37-A. Ligand exchange and isomerization under basic conditions produce either the $\alpha$-pallado ketone 37-C or the palladium enolate 37-D [80]. The results of DFT calculations suggested that the transformation proceeds through a pathway of reductive elimination of 37-C (Path A in Scheme 37) instead of nucleophilic addition of 37D (Path B in Scheme 37). As to the enantioselectivity of the reaction, the transition state of the Re-face is characterized by lower free energy than that of the Si-face (the difference was calculated to be $2.7 \mathrm{kcal} / \mathrm{mol}$ ), which was consistent with the observed values for the enantioselectivity (an ee

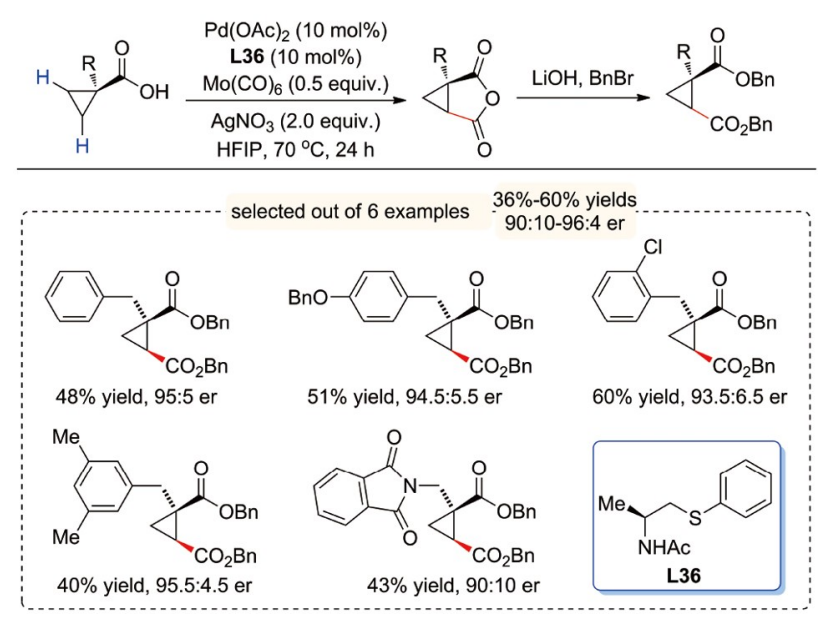

Scheme 36 Pd-catalyzed enantioselective $\mathrm{C}\left(\mathrm{sp}^{3}\right)-\mathrm{H}$ functionalization of carboxylic acids (color online).

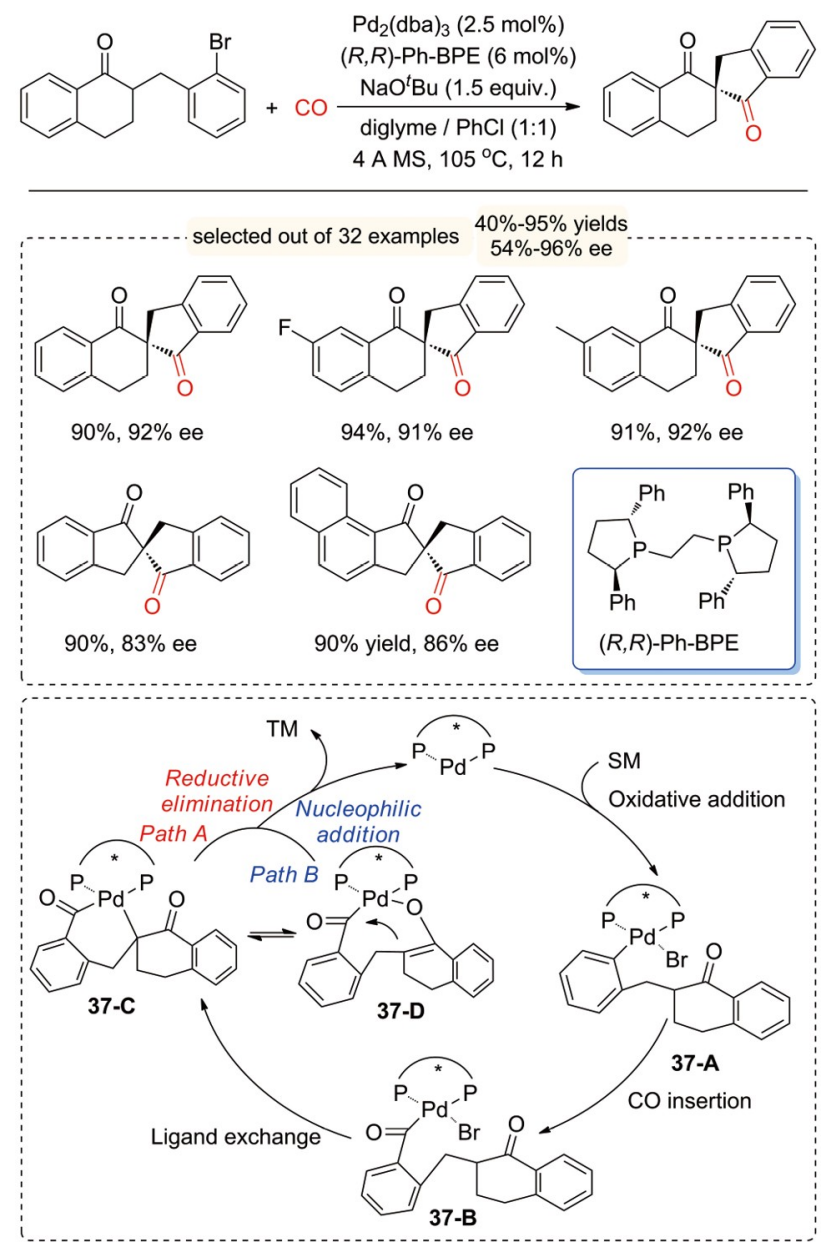

Scheme 37 Pd-catalyzed enantioselective $\alpha$-carbonylative arylation (color online).

value of $90 \%$ corresponds to a $\Delta \Delta G_{\exp }$ value of $2.1 \mathrm{kcal} / \mathrm{mol}$ at $\left.90{ }^{\circ} \mathrm{C}\right)$.

Implementation of organo-catalyzed cascade reactions has afforded a great deal of success, given their efficiency and 
sustainability in the synthesis of complex organic molecules [81]. Used in combination, organo-catalysts and metal catalysts could complement each other and permit chemical transformations that are not achievable by either of the catalysts alone [82]. Han, Gong, and co-workers [83] developed an asymmetric formal $[1+1+4]$ and $[1+1+2]$ annulation reaction of benzyl bromides, $\mathrm{CO}$, and $N$-tosylimines for the synthesis of chiral dihydropyridones and $\beta$-lactams by combining Pd-catalyzed carbonylation and chiral Lewis base catalysis (Scheme 38). In the presence of the Pd catalyst and chiral benzotetramisole (BTM), the reactions afforded excellent yields (up to 99\%) and enantioselectivities (up to $99 \%$ ee). The key to these transformations was the formation of the $\mathrm{C} 1$-ammonium enolates by integrating the Pd-catalyzed carbonylation and chiral Lewis base catalysis. The oxidative addition of the $\mathrm{Pd}^{0}$ catalyst to benzyl bromide followed by $\mathrm{CO}$ insertion generated an acyl-palladium intermediate, which was transformed into the corresponding ketene through $\beta$-hydride elimination. Subsequently, the ketene reacted with the BTM catalyst to form the key C1-ammonium enolate intermediate, which underwent stereoselective cascade cyclization to generate the corresponding products.

\section{Summary and outlook}

The development of stereoselective asymmetric transformations of organic compounds is a fascinating subject as well as a challenging goal of modern synthetic chemistry. The 2001 Nobel Prize in chemistry was awarded to Knowles, Noyori, and Sharpless in recognition of their research work in asymmetric metal catalysis. The Nobel Prize in Chemistry 2021 was awarded to List and Macmillan in recognition of their outstanding contributions in the research field of "asymmetric organic catalysis." Over the past two decades, a great deal of success has also been achieved in the field of enantioselective carbonylation reactions. In particular, the Pd-catalyzed asymmetric carbonylation reaction provides broad opportunities to accomplish these transformations. In this review, we have summarized and discussed the recent achievements in Pd-catalyzed asymmetric carbonylation reactions.

Notably, compared with the well-established enantioselective hydrogenation and hydroformylation reactions, the lack of efficient chiral catalysts and the low efficiency of catalysts, in general, are common problems in Pd-catalyzed asymmetric carbonylation reactions. The development of new asymmetric catalytic systems, including chiral catalysts, chiral ligands, and chiral additives, are the three main aspects to introduce chirality into the carbonylation product (Scheme 39).

At the present time, a number of problems are still left to be solved. For example, the reactions' generally low ste-
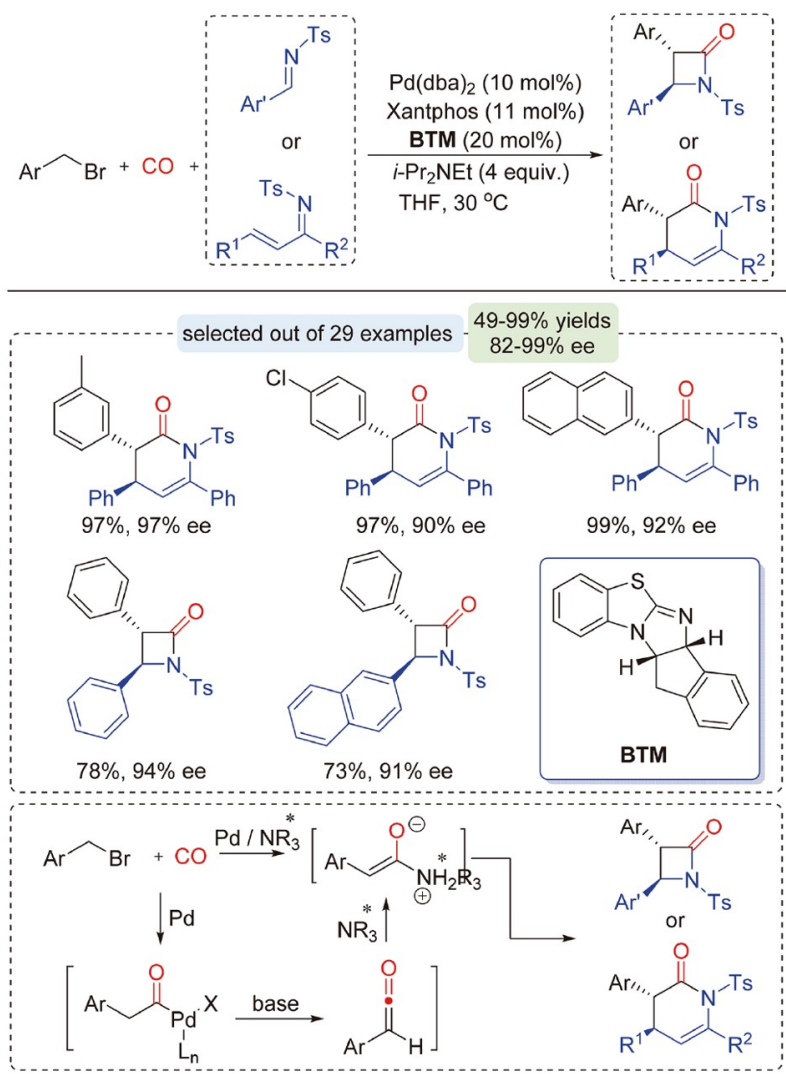

Scheme 38 Palladium-catalyzed carbonylation combined with chiral Lewis base catalysis (color online).

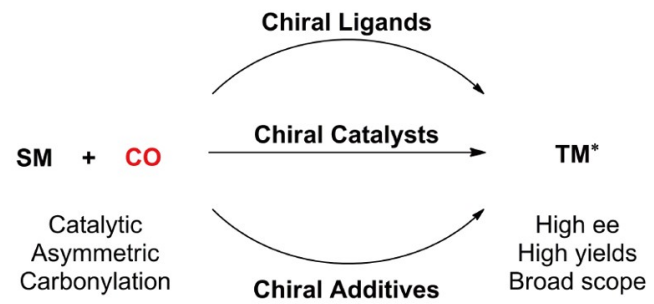

Scheme 39 General strategies for asymmetric carbonylation (color online).

reoselectivity and the catalytic efficiency, and several objectives need to be achieved, including the development of new efficient chiral catalysts, the complex multi-factor control of the process of chiral induction, and the inhibition of racemization under harsh reaction conditions. Therefore, the preparation of new chiral catalysts, the development of new and efficient chiral catalytic reactions, and the innovation of theory and method will be important aspects to focus on to achieve high selectivity and high efficiency in asymmetric carbonylations. Hopefully, this review can contribute to the further development of this area of research.

Acknowledgements This work was supported by the National Natural Science Foundation of China (21801225), the Science Foundation for Young Teachers (2019td02), High-level Talent Research Start-up Project 
(2018TP018) of Wuyi University, the Guangdong Province Universities and Colleges Pearl River Scholar Funded Scheme (2019), and the Department of Education of Guangdong Province (2020KCXTD036).

Conflict of interest The authors declare no conflict of interest.

Open Access This article is distributed under the terms of the Creative Commons Attribution 4.0 International License (http://creativecommons. org/licenses/by/4.0/), which permits unrestricted use, distribution, and reproduction in any medium, provided you give appropriate credit to the original author(s) and the source, provide a link to the Creative Commons license, and indicate if changes were made.

1 (a) Beller M. Catalytic Carbonylation Reactions. Berlin: Springer, 2006; (b) Kollar L. Modern Carbonylation Methods. Weinheim: Wiley-VCH, 2008; (c) Beller M, Wu X-F. Transition Metal Catalyzed Carbonylation Reactions: Carbonylative Activation of $C-X$ Bonds. Amsterdam: Springer, 2013; (d) Bertoux F, Monflier E, Castanet Y, Mortreux A. J Mol Catal A-Chem, 1999, 143: 11-22; (e) Kiss G. Chem Rev, 2001, 101: 3435-3456; (f) Barnard CFJ. Organometallics, 2008, 27: 5402-5422; (g) Wu XF, Neumann H, Beller M. Chem Soc Rev, 2011, 40: 4986-5009; (h) Liu Q, Zhang H, Lei A. Angew Chem Int Ed, 2011, 50: 10788-10799; (i) Gabriele B, Mancuso R, Salerno G. Eur J Org Chem, 2012, 2012(35): 6825-6839; (j) Wu XF, Neumann H, Beller M. Chem Rev, 2013, 113: 1-35; (k) Wu XF, Fang X, Wu L, Jackstell R, Neumann H, Beller M. Acc Chem Res, 2014, 47: 1041-1053; (1) Wu XF. RSC Adv, 2016, 6: 83831-83837; (m) Peng JB, Wu XF. Angew Chem Int Ed, 2018, 57: 1152-1160; (n) Li Y, Hu Y, Wu XF. Chem Soc Rev, 2018, 47: 172-194; (o) Peng JB, Wu FP, Wu XF. Chem Rev, 2019, 119: 2090-2127; (p) Peng JB, Geng HQ, Wu XF. Chem, 2019, 5: 526-552; (q) Peng J. Adv Synth Catal, 2020, 362: $3059-3080$

2 (a) Gehrtz P, Hirschbeck V, Ciszek B, Fleischer I. Synthesis, 2016, 48: 1573-1596; (b) Bai Y, Davis DC, Dai M. J Org Chem, 2017, 82: 2319-2328; (c) Ma K, Martin BS, Yin X, Dai M. Nat Prod Rep, 2019, 36: $174-219$

3 (a) Ganji P, Doyle DJ, Ibrahim H. Org Lett, 2011, 13: 3142-3145; (b) Ganji P, Ibrahim H. Chem Commun, 2012, 48: 10138-10140; (c) Yuan Y, Wu FP, Schünemann C, Holz J, Kamer PCJ, Wu XF. Angew Chem Int Ed, 2020, 59: 22441-22445; (d) Yuan Y, Zhao F, Wu XF. Chem Sci, 2021, 12: 12676-12681; (e) Chen J, Zhu S. J Am Chem Soc, 2021, 143: 14089-14096

4 (a) Klosin J, Landis CR. Acc Chem Res, 2007, 40: 1251-1259; (b) Franke R, Selent D, Börner A. Chem Rev, 2012, 112: 5675-5732; (c) Pospech J, Fleischer I, Franke R, Buchholz S, Beller M. Angew Chem Int Ed, 2013, 52: 2852-2872; (d) Deng Y, Wang H, Sun Y, Wang X. ACS Catal, 2015, 5: 6828-6837; (e) Borner A, Franke R. Hydroformylation: Fundamentals, Processes, and Applications in Organic Synthesis. Weinheim: Wiley-VCH, 2016; (f) Bauder C, Sémeril D. Eur J Inorg Chem, 2019, 2019(47): 4951-4965; (g) Li S, Li Z, You C, Lü H, Zhang X. Chin J Org Chem, 2019, 39: 1568-1582

5 (a) Leeuwen PWNMV. Homogeneous Catalysis. Understanding the Art. Dordrecht: Kluwer Academic Publishers, 2004; (b) Botteghi C, Consiglio G, Pino P. Chimia, 1973, 27: 477-478; (c) Consiglio G. Helv Chim Acta, 1976, 59: 124-126; (d) Consiglio G. J Organomet Chem, 1977, 132: C26-C28; (e) Hayashi T, Tanaka M, Ogata I. Tetrahedron Lett, 1978, 19: 3925-3926; (f) Becker Y, Eisenstadt A, Stille JK. J Org Chem, 1980, 45: 2145-2151; (g) Cometti G, Chiusoli GP. J Organomet Chem, 1982, 236: C31-C32; (h) Alper H, Hamel N. J Am Chem Soc, 1990, 112: 2803-2804; (i) Chelucci G, Cabras MA, Botteghi C, Marchetti M. Tetrahedron-Asymmetry, 1994, 5: 299-302; (j) Zhou H, Lu S, Hou J, Chen J, Fu H, Wang H. Chem Lett, 1996, 25: 339-340; (k) Zhou H, Hou J, Cheng J, Lu S, Fu H, Wang H. J Organomet Chem, 1997, 543: 227-228; (1) Oi S, Nomura M, Aiko T, Inoue Y. J Mol Catal A-Chem, 1997, 115: 289-295; (m) Nozaki K,
Kantam ML, Horiuchi T, Takaya H. J Mol Catal A-Chem, 1997, 118: 247-253; (n) Miquel-Serrano MD, Aghmiz A, Diéguez M, MasdeuBultó AM, Claver C, Sinou D. Tetrahedron-Asymmetry, 1999, 10 : 4463-4467; (o) Wang L, Kwok WH, Chan ASC, Tu T, Hou X, Dai L. Tetrahedron-Asymmetry, 2003, 14: 2291-2295; (p) Kawashima Y, Okano K, Nozaki K, Hiyama T. Bull Chem Soc Jpn, 2004, 77: 347355; (q) Muñoz B, Marinetti A, Ruiz A, Castillon S, Claver C. InOrg Chem Commun, 2005, 8: 1113-1115; (r) Guiu E, Caporali M, Muñoz B, Müller C, Lutz M, Spek AL, Claver C, van Leeuwen PWNM. Organometallics, 2006, 25: 3102-3104; (s) Godard C, Ruiz A, Claver C. Helv Chim Acta, 2006, 89: 1610-1622; (t) Muñoz BK, Godard C, Marinetti A, Ruiz A, Benet-Buchholz J, Claver C. Dalton Trans, 2007, 5524-5530; (u) Yu WY, Bensimon C, Alper H. Chem Eur J, 1997, 3: 417-423; (v) Dong C, Alper H. J Org Chem, 2004, 69: 5011-5014

6 (a) Alper H, Hamel N. J Am Chem Soc, 1990, 112: 2803-2804; (b) Kawashima Y, Okano K, Nozaki K, Hiyama T. Bull Chem Soc Jpn, 2004, 77: 347-355; (c) Kalck P, Urrutigoïty M. Inorg Chim Acta, 2015, 431: 110-121

7 (a) Konrad TM, Fuentes JA, Slawin AMZ, Clarke ML. Angew Chem Int Ed, 2010, 49: 9197-9200; (b) Konrad TM, Durrani JT, Cobley CJ, Clarke ML. Chem Commun, 2013, 49: 3306-3308; (c) Fuentes JA, Durrani JT, Leckie SM, Crawford LE, Bühl M, Clarke ML. Catal Sci Technol, 2016, 6: 7477-7485

8 Harkness GJ, Clarke ML. Eur J Org Chem, 2017, 2017(32): 48594863

9 Gallarati S, Dingwall P, Fuentes JA, Bühl M, Clarke ML. Organometallics, 2020, 39: 4544-4556

10 (a) Li J, Chang W, Ren W, Dai J, Shi Y. Org Lett, 2016, 18: 54565459; (b) Li J, Ren W, Dai J, Shi Y. Org Chem Front, 2018, 5: 75-79

11 Ren X, Wang Z, Shen C, Tian X, Tang L, Ji X, Dong K. Angew Chem Int $E d, 2021,60$ : 17693-17700

12 (a) Alper H, Leonard D. Tetrahedron Lett, 1985, 26: 5639-5642; (b) Alper H, Hamel N. J Chem Soc Chem Commun, 1990, 1: 135-136; (c) El Ali B, Alper H. J Org Chem, 1991, 56: 5357-5360; (d) El Ali B, Okuro K, Vasapollo G, Alper H. J Am Chem Soc, 1996, 118: 4264 4270; (e) Brunner M, Alper H. J Org Chem, 1997, 62: 7565-7568

13 (a) Dekker GPCM, Elsevier CJ, Vrieze K, Van Leeuwen PWNM. Organometallics, 1992, 11: 1598-1603; (b) Dekker GPCM, Elsevier CJ, Vrieze K, van Leeuwen PWNM, Roobeek CF. J Organomet Chem, 1992, 430: 357-372

14 Yu WY, Bensimon C, Alper H. Chem Eur J, 1997, 3: 417-423

15 (a) Zhu G, Cao P, Jiang Q, Zhang X. J Am Chem Soc, 1997, 119: 1799-1800; (b) Zhu G, Casalnuovo AL, Zhang X. J Org Chem, 1998, 63: 8100-8101; (c) Zhu G, Zhang X. J Org Chem, 1998, 63: 95909593; (d) Cao P, Zhang X. J Org Chem, 1999, 64: 2127-2129

16 Cao P, Zhang X. J Am Chem Soc, 1999, 121: 7708-7709

17 Wang H, Dong B, Wang Y, Li J, Shi Y. Org Lett, 2014, 16: 186-189

18 Lipshutz BH, Lower A, Noson K. Org Lett, 2002, 4: 4045-4048

19 Li J, Chang W, Ren W, Liu W, Wang H, Shi Y. Org Biomol Chem, 2015, 13: 10341-10347

20 Tian D, Xu R, Zhu J, Huang J, Dong W, Claverie J, Tang W. Angew Chem Int Ed, 2021, 60: 6305-6309

21 (a) Qian C, Tang W. Org Lett, 2020, 22: 4483-4488; (b) Liu G, Liu X, Cai Z, Jiao G, Xu G, Tang W. Angew Chem Int Ed, 2013, 52: 42354238; (c) Xu G, Senanayake CH, Tang W. Acc Chem Res, 2019, 52 : 1101-1112

22 Castarlenas R, Di Giuseppe A, Pérez-Torrente JJ, Oro LA. Angew Chem Int Ed, 2013, 52: 211-222

23 Xiao WJ, Alper H. J Org Chem, 2001, 66: 6229-6233

24 Wang X, Wang B, Yin X, Yu W, Liao Y, Ye J, Wang M, Hu L, Liao J. Angew Chem Int Ed, 2019, 58: 12264-12270

25 (a) Jia T, Cao P, Wang B, Lou Y, Yin X, Wang M, Liao J. J Am Chem Soc, 2015, 137: 13760-13763; (b) Chen B, Cao P, Yin X, Liao Y, Jiang L, Ye J, Wang M, Liao J. ACS Catal, 2017, 7: 2425-2429; (c) Chen B, Cao P, Liao Y, Wang M, Liao J. Org Lett, 2018, 20: 1346-1349

26 (a) Fang X, Jackstell R, Beller M. Angew Chem Int Ed, 2013, 52: 
14089-14093; (b) Li H, Dong K, Neumann H, Beller M. Angew Chem Int Ed, 2015, 54: 10239-10243; (c) Liu J, Li H, Spannenberg A, Franke R, Jackstell R, Beller M. Angew Chem Int Ed, 2016, 55: 13544-13548; (d) Jiménez-Rodriguez C, Núñez-Magro AA, Seidensticker T, Eastham GR, Furst MRL, Cole-Hamilton DJ. Catal Sci Technol, 2014, 4: 2332-2339; (e) Liu H, Yan N, Dyson PJ. Chem Commun, 2014, 50: 7848-7851; (f) Zhang G, Gao B, Huang H. Angew Chem Int Ed, 2015, 54: 7657-7661; (g) Hu Y, Shen Z, Huang H. ACS Catal, 2016, 6: 6785-6789; (h) Gao B, Zhang G, Zhou X, Huang H. Chem Sci, 2018, 9: 380-386; (i) Li J, Wang S, Zou S, Huang H. Commun Chem, 2019, 2: 14; (j) Zhu J, Gao B, Huang H. Org Biomol Chem, 2017, 15: 2910-2913; (k) Xu T, Sha F, Alper H. J Am Chem Soc, 2016, 138: 6629-6635; (1) Dong K, Fang X, Jackstell R, Laurenczy G, Li Y, Beller M. J Am Chem Soc, 2015, 137: 6053-6058; (m) Yuan Y, Wu FP, Schünemann C, Holz J, Kamer PCJ, Wu XF. Angew Chem Int Ed, 2020, 59: 22441-22445

27 Yao YH, Yang HY, Chen M, Wu F, Xu XX, Guan ZH. J Am Chem Soc, 2021, 143: 85-91

28 Tietze LF, Spiegl DA, Stecker F, Major J, Raith C, Grosse C. Chem Eur J, 2008, 14: 8956-8963

29 Tietze LF, Ma L, Reiner JR, Jackenkroll S, Heidemann S. Chem Eur J, 2013, 19: 8610-8614

30 Tietze LF, Jackenkroll S, Raith C, Spiegl DA, Reiner JR, Ochoa Campos MC. Chem Eur J, 2013, 19: 4876-4882

31 Tietze LF, Jackenkroll S, Hierold J, Ma L, Waldecker B. Chem Eur J, 2014, 20: 8628-8635

32 (a) Tietze LF, Ma L, Jackenkroll S, R. Reiner J, Hierold J, Gnanaprakasam B, Heidemann S. Heterocycles, 2014, 88: 1101-1119; (b) Tietze L, Jackenkroll S, Ganapathy D, Reiner J. Synlett, 2016, 27: 96100

33 Li M, Yu F, Qi X, Chen P, Liu G. Angew Chem Int Ed, 2016, 55: 13843-13848

34 (a) Yin G, Mu X, Liu G. Acc Chem Res, 2016, 49: 2413-2423; (b) Qi X, Chen C, Hou C, Fu L, Chen P, Liu G. J Am Chem Soc, 2018, 140: 7415-7419; (c) Chen C, Pflüger PM, Chen P, Liu G. Angew Chem Int Ed, 2019, 58: 2392-2396; (d) Hou C, Chen P, Liu G. Angew Chem Int Ed, 2020, 59: 2735-2739

35 Tian B, Li X, Chen P, Liu G. Angew Chem Int Ed, 2021, 60: 1488114886

36 (a) Zimmer R, Dinesh CU, Nandanan E, Khan FA. Chem Rev, 2000, 100: 3067-3126; (b) Lechel T, Pfrengle F, Reissig HU, Zimmer R. ChemCatChem, 2013, 5: 2100-2130

37 Liu J, Han Z, Wang X, Wang Z, Ding K. J Am Chem Soc, 2015, 137: $15346-15349$

38 (a) Wang X, Han Z, Wang Z, Ding K. Angew Chem Int Ed, 2012, 51: 936-940; (b) Wang X, Guo P, Wang X, Wang Z, Ding K. Adv Synth Catal, 2013, 355: 2900-2907; (c) Cao ZY, Wang X, Tan C, Zhao XL, Zhou J, Ding K. J Am Chem Soc, 2013, 135: 8197-8200; (d) Wang X, Meng F, Wang Y, Han Z, Chen YJ, Liu L, Wang Z, Ding K. Angew Chem Int Ed, 2012, 51: 9276-9282; (e) Wang X, Guo P, Han Z, Wang X, Wang Z, Ding K. J Am Chem Soc, 2014, 136: 405-411

39 (a) Fenton DMS. Ester production from olefins by oxidative carbonylation using palladium and copper catalysts in alcohol. US Patent 3 397, 1968; (b) Yukawa T, Tsutsumi S. J Org Chem, 1969, 34: 738740; (c) Fenton DM, Steinwand PJ. J Org Chem, 1972, 37: 20342035; (d) Heck RF. J Am Chem Soc, 1972, 94: 2712-2716

40 Pisano C, Nefkens SCA, Consiglio G. Organometallics, 1992, 11: 1975-1978

41 Nefkens SCA, Sperrle M, Consiglio G. Angew Chem Int Ed, 1993, 32: $1719-1720$

42 Wang L, Kwok W, Wu J, Guo R, Au-Yeung TTL, Zhou Z, Chan ASC, Chan KS. J Mol Catal A-Chem, 2003, 196: 171-178

43 (a) Takeuchi S, Ukaji Y, Inomata K. Bull Chem Soc Jpn, 2001, 74: 955-958; (b) Aratani T, Tahara K, Takeuchi S, Kitamura S, Murai M, Fujinami S, Inomata K, Ukaji Y. Bull Chem Soc Jpn, 2012, 85: 12251232

44 (a) Nan Y, Miao H, Yang Z. Org Lett, 2000, 2: 297-299; (b) Dai M,
Wang C, Dong G, Xiang J, Luo T, Liang B, Chen J, Yang Z. Eur J Org Chem, 2003, 2003(22): 4346-4348; (c) Dai M, Liang B, Wang C, You Z, Xiang J, Dong G, Chen J, Yang Z. Adv Synth Catal, 2004, 346: 1669-1673; (d) Tang Y, Deng L, Zhang Y, Dong G, Chen J, Yang Z. Org Lett, 2005, 7: 1657-1659

45 Liang B, Liu J, Gao YX, Wongkhan K, Shu DX, Lan Y, Li A, Batsanov AS, Howard JAH, Marder TB, Chen JH, Yang Z. Organometallics, 2007, 26: 4756-4762

46 Gao Y, Chang L, Shi H, Liang B, Wongkhan K, Chaiyaveij D, Batsanov A, Marder T, Li C, Yang Z, Huang Y. Adv Synth Catal, 2010, 352: $1955-1966$

47 (a) Negishi E, Miller JA. J Am Chem Soc, 1983, 105: 6761-6763; (b) Tour JM, Negishi E. J Am Chem Soc, 1985, 107: 8289-8291; (c) Wu G, Shimoyama I, Negishi E. J Org Chem, 1991, 56: 65066507; (d) Negishi E, Copéret C, Ma S, Mita T, Sugihara T, Tour JM. J Am Chem Soc, 1996, 118: 5904-5918; (e) Negishi E, Ma S, Amanfu J, Copéret C, Miller JA, Tour JM. J Am Chem Soc, 1996, 118: 59195931; (f) Copéret C, Ma S, Negishi E. Angew Chem Int Ed, 1996, 35 : $2125-2126$

48 Hayashi T, Tang J, Kato K. Org Lett, 1999, 1: 1487-1489

49 Matsuura T, Overman LE, Poon DJ. J Am Chem Soc, 1998, 120: $6500-6503$

50 Carmona RC, Köster OD, Correia CRD. Angew Chem Int Ed, 2018, 57: $12067-12070$

51 Hu H, Teng F, Liu J, Hu W, Luo S, Zhu Q. Angew Chem Int Ed, 2019, 58: 9225-9229

52 Yuan Z, Zeng Y, Feng Z, Guan Z, Lin A, Yao H. Nat Commun, 2020, 11: 2544-2551

53 Chen M, Wang X, Yang P, Kou X, Ren ZH, Guan ZH. Angew Chem Int $E d, 2020$, 59: 12199-12205

54 (a) Thomas AA, Denmark SE. Science, 2016, 352: 329-332; (b) Thomas AA, Wang H, Zahrt AF, Denmark SE. J Am Chem Soc, 2017, 139: 3805-3821; (c) Carrow BP, Hartwig JF. J Am Chem Soc, 2011, 133: 2116-2119

55 Cheng C, Wan B, Zhou B, Gu Y, Zhang Y. Chem Sci, 2019, 10: $9853-$ 9858

56 (a) Morimoto T, Kakiuchi K. Angew Chem Int Ed, 2004, 43: 55805588; (b) Konishi H, Manabe K. Synlett, 2014, 1971-1986; (c) Wu L, Liu Q, Jackstell R, Beller M. Angew Chem Int Ed, 2014, 53: 63106320; (d) Gautam P, Bhanage BM. Catal Sci Technol, 2015, 5: 46634702; (e) Peng JB, Qi X, Wu XF. Synlett, 2017, 28: 175-194

$57 \mathrm{Hu} \mathrm{H}$, Peng Y, Yu T, Cheng S, Luo S, Zhu Q. Org Lett, 2021, 23 : 3636-3640

58 (a) Marshall JA, Wallace EM, Coan PS. J Org Chem, 1995, 60: 796797; (b) Marshall JA, Bartley GS, Wallace EM. J Org Chem, 1996, 61: 5729-5735

59 Marshall JA, Wolf MA, Wallace EM. J Org Chem, 1997, 62: 367-371

60 Wang Y, Ma S. Adv Synth Catal, 2013, 355: 741-750

61 Wang Y, Zhang W, Ma S. J Am Chem Soc, 2013, 135: 11517-11520

62 Xu Z, Shen C, Zhang H, Wang P, Dong K. Org Chem Front, 2021, 8: 1163-1169

63 (a) Franzén J, Löfstedt J, Dorange I, Bäckvall JE. J Am Chem Soc, 2002, 124: 11246-11247; (b) Franzén J, Bäckvall JE. J Am Chem Soc, 2003, 125: 6056-6057; (c) Franzén J, Löfstedt J, Falk J, Bäckvall JE. $J$ Am Chem Soc, 2003, 125: 14140-14148; (d) Persson AKA, Bäckvall JE. Angew Chem Int Ed, 2010, 49: 4624-4627; (e) Jiang T, Persson AKÅ, Bäckvall JE. Org Lett, 2011, 13: 5838-5841; (f) Persson AKÅ, Jiang T, Johnson MT, Bäckvall JE. Angew Chem Int Ed, 2011, 50: 6155-6159; (g) Persson AKÅ, Jiang T, Johnson MT, Bäckvall JE. Angew Chem, 2011, 123: 6279-6283; (h) Qiu Y, Yang B, Zhu C, Bäckvall JE. Angew Chem Int Ed, 2016, 55: 6520-6524

64 Zhu C, Yang B, Bäckvall JE. J Am Chem Soc, 2015, 137: 1186811871

65 (a) Jiang T, Bartholomeyzik T, Mazuela J, Willersinn J, Bäckvall JE. Angew Chem Int Ed, 2015, 54: 6024-6027; (b) Jiang G, List B. Angew Chem Int Ed, 2011, 50: 9471-9474; (c) Wang PS, Lin HC, Zhai YJ, Han ZY, Gong LZ. Angew Chem Int Ed, 2014, 53: 12218-12221 
66 (a) Deng X, Shi LY, Lan J, Guan YQ, Zhang X, Lv H, Chung LW, Zhang X. Nat Commun, 2019, 10: 949-959; (b) Masutomi K, Noguchi K, Tanaka K. J Am Chem Soc, 2014, 136: 7627-7630; (c) Nicolaou KC, Li A, Ellery SP, Edmonds DJ. Angew Chem Int Ed, 2009, 48: 6293-6295; (d) Trost BM, Ryan MC, Rao M, Markovic TZ. J Am Chem Soc, 2014, 136: 17422-17425; (e) Dieckmann M, Jang YS, Cramer N. Angew Chem Int Ed, 2015, 54: 12149-12152; (f) Liang RX, Song LJ, Lu JB, Xu WY, Ding C, Jia YX. Angew Chem Int Ed, 2021, 60: 7412-7417; (g) Jang HY, Hughes FW, Gong H, Zhang J, Brodbelt JS, Krische MJ. J Am Chem Soc, 2005, 127: 6174-6175; (h) Wang C, Ge S. J Am Chem Soc, 2018, 140: 10687-10690; (i) Yu S, Wu C, Ge S. J Am Chem Soc, 2017, 139: 6526-6529; (j) Fan BM, Xie JH, Li S, Wang LX, Zhou QL. Angew Chem Int Ed, 2007, 46: 1275-1277; (k) Whyte A, Torelli A, Mirabi B, Prieto L, Rodríguez JF, Lautens M. J Am Chem Soc, 2020, 142: 9510-9517; (1) Whyte A, Bajohr J, Torelli A, Lautens M. Angew Chem Int Ed, 2020, 59: 1640916413

67 Ren X, Tang L, Shen C, Li H, Wang P, Dong K. Org Lett, 2021, 23: 3561-3566

68 Bai XF, Mu QC, Xu Z, Yang KF, Li L, Zheng ZJ, Xia CG, Xu LW. ACS Catal, 2019, 9: 1431-1436

69 (a) Chu L, Xiao KJ, Yu JQ. Science, 2014, 346: 451-455; (b) Xiao KJ, Chu L, Yu JQ. Angew Chem Int Ed, 2016, 55: 2856-2860

70 Han H, Zhang T, Yang SD, Lan Y, Xia JB. Org Lett, 2019, 21: 17491754

71 Li Y, Cheng XF, Fei F, Wu TR, Bian KJ, Zhou X, Wang XS. Chem Commun, 2020, 56: 11605-11608

$72 \mathrm{Mu}$ QQ, Nie YX, Li H, Bai XF, Liu XW, Xu Z, Xu LW. Chem Commun, 2021, 57: 1778-1781

73 Dailler D, Rocaboy R, Baudoin O. Angew Chem Int Ed, 2017, 56: 7218-7222

74 Dong W, Xu G, Tang W. Tetrahedron, 2019, 75: 3239-3247

75 (a) Wang C, Zhang L, Chen C, Han J, Yao Y, Zhao Y. Chem Sci, 2015, 6: 4610-4614; (b) Wang PL, Li Y, Wu Y, Li C, Lan Q, Wang XS. Org Lett, 2015, 17: 3698-3701; (c) Hernando E, Villalva J, Martínez ÁM, Alonso I, Rodríguez N, Gómez Arrayás R, Carretero
JC. ACS Catal, 2016, 6: 6868-6882

76 Zhuang Z, Yu JQ. J Am Chem Soc, 2020, 142: 12015-12019

77 Zhuang Z, Herron AN, Yu JQ. Angew Chem Int Ed, 2021, 60: 1638216387

78 (a) Kobayashi T, Tanaka M. Tetrahedron Lett, 1986, 27: 4745-4748; (b) Negishi E, Copéret C, Sugihara T, Shimoyama I, Zhang Y, Wu G, Tour JM. Tetrahedron, 1994, 50: 425-436; (c) Negishi E, Makabe H, Shimoyama I, Wu G, Zhang Y. Tetrahedron, 1998, 54: 1095-1106; (d) Zheng Z, Alper H. Org Lett, 2009, 11: 3278-3281; (e) Schranck J, Tlili A, Neumann H, Alsabeh PG, Stradiotto M, Beller M. Chem Eur J, 2012, 18: 15592-15597; (f) Korsager S, Nielsen DU, Taaning RH, Skrydstrup T. Angew Chem Int Ed, 2013, 52: 9763-9766; (g) Korsager S, Nielsen DU, Taaning RH, Lindhardt AT, Skrydstrup T. Chem Eur J, 2013, 19: 17687-17691; (h) Nielsen DU, Korsager S, Lindhardt AT, Skrydstrup T. Adv Synth Catal, 2014, 356: 3519-3524; (i) Jusseau X, Yin H, Lindhardt AT, Skrydstrup T. Chem Eur J, 2014, 20: 15785-15789; (j) Lian Z, Friis SD, Skrydstrup T. Angew Chem Int Ed, 2014, 53: 9582-9586; (k) Lian Z, Friis SD, Skrydstrup T. Chem Commun, 2015, 51: 3600-3603; (1) Schranck J, Burhardt M, Bornschein C, Neumann H, Skrydstrup T, Beller M. Chem Eur J, 2014, 20: 9534-9538

79 Wu T, Zhou Q, Tang W. Angew Chem Int Ed, 2021, 60: 9978-9983

80 (a) Gøgsig TM, Taaning RH, Lindhardt AT, Skrydstrup T. Angew Chem Int Ed, 2012, 51: 798-801; (b) Nielsen DU, Lescot C, Gøgsig TM, Lindhardt AT, Skrydstrup T. Chem Eur J, 2013, 19: 1792617938

81 (a) Wang Y, Lu H, Xu PF. Acc Chem Res, 2015, 48: 1832-1844; (b) Grondal C, Jeanty M, Enders D. Nat Chem, 2010, 2: 167-178; (c) MacMillan DWC. Nature, 2008, 455: 304-308; (d) List B. Chem Rev, 2007, 107: 5413-5415; (e) Enders D, Hüttl MRM, Grondal C, Raabe G. Nature, 2006, 441: 861-863

82 (a) Chen DF, Han ZY, Zhou XL, Gong LZ. Acc Chem Res, 2014, 47: 2365-2377; (b) Du Z, Shao Z. Chem Soc Rev, 2013, 42: 1337-1378; (c) Afewerki S, Córdova A. Chem Rev, 2016, 116: 13512-13570

83 Li LL, Ding D, Song J, Han ZY, Gong LZ. Angew Chem Int Ed, 2019, 58: 7647-7651 